Article

\title{
Literature Review on Digitalization in Facilities Management and Facilities Management Performance Measurement: Contribution of Industry 4.0 in the Global Era
}

\author{
Jeoung Yul Lee ${ }^{1,2}$, Ilkhom Okmirzaevich Irisboev ${ }^{1, *}$ and Yeon-Sik Ryu ${ }^{1, *}$ \\ 1 School of Business Management, Hongik University, Sejong 30016, Korea; jeoungyul@hongik.ac.kr \\ 2 National Research Base of Intelligent Manufacturing Service, Chongqing Technology and Business University, \\ Chongqing 400067, China \\ * Correspondence: ilkhomirisboev@gmail.com (I.O.I.); bluerys@mail.hongik.ac.kr (Y.-S.R.)
}

check for updates

Citation: Lee, J.Y.; Irisboev, I.O.; Ryu, Y.-S. Literature Review on Digitalization in Facilities

Management and Facilities Management Performance Measurement: Contribution of Industry 4.0 in the Global Era. Sustainability 2021, 13, 13432. https://doi.org/10.3390/su132313432

Academic Editor: Sunkuk Kim

Received: 30 October 2021

Accepted: 2 December 2021

Published: 4 December 2021

Publisher's Note: MDPI stays neutral with regard to jurisdictional claims in published maps and institutional affiliations.

Copyright: (C) 2021 by the authors. Licensee MDPI, Basel, Switzerland. This article is an open access article distributed under the terms and conditions of the Creative Commons Attribution (CC BY) license (https:// creativecommons.org/licenses/by/ $4.0 /)$.

\begin{abstract}
In this study, our aim is to present a comprehensive systematic review on digitalization (DT) in facility management (FM) and FM performance management (PM). Past research on these themes indicated that either research articles on DT in FM or research studies on FM PM are separately dealt with. However, in contrast, in our literature review, we try to present a holistic literature review by integrating both research streams on DT applications for FM and FM PM. A total 130 academic journal articles published on these subjects, between 1990 and 2021, from Web of Science and Google Scholars, were reviewed in this article. Moreover, this article identified a number of possibilities for future research on DT and FM PM, including the interoperability enhancement of building information modeling (BIM) methodology, the test and implementation of BIM concept for smart transportation infrastructure, usage of the integration of $3 \mathrm{D}$ analysis algorithms, the perfect cross integration of BIM and geographic information system (GIS) and systematic research efforts with new methodologies and theoretical constructs. We hope that this article will help researchers determine the areas where further research must be conducted and what kind of future directions would be valuable for DT and PM in FM.
\end{abstract}

Keywords: facilities management; digitalization; performance measurement; sustainability; literature review

\section{Introduction}

The International Standard Organization (ISO) [1] defines facilities management (FM) as an organizational function that integrates people, place and process within the built environment with the purpose of improving the quality of people's life and the productivity of the core business. In addition, International Facility Management Association (IFMA) [2] defines FM as a profession that encompasses multiple disciplines to ensure functionality, comfort, safety and efficiency of the built environment by integrating people, place, process and technology. Pilanawithana and Sandanayake [3] also defined FM as "a dynamic profession that supports core business functions by creating a cost-effective, risk-free deployment environment tailored to strategic business guidelines throughout the building lifecycle" (p. 376). In general, facilities among FMs include various types of physical infrastructure and buildings [4]. In addition, there are broad and diverse definitions through many different studies and the practical relationship between organizations in all sectors of the economy, and FM is increasingly gaining recognition and attention. In particular, the importance of FM is increasing further due to the flexibility provided to organizations in the rapidly changing era [5]. FM's biggest purpose is basically to continuously support the organization's need for physical resources and support services $[5,6]$, and the success of FM ultimately depends on the degree to which the facility supports the "business" operation [5]. 
Digitalization (DT) has had a great influence on the way existing everyday functions are performed in various traditional industries. It has revolutionized most knowledgebased industries, which have had a faster and greater impact, especially due to improved access to various information and accelerated communication speed [7]. Mirarchi et al. [8] proposed a theoretical framework for integrating digital technology into facility management (FM). Especially, it is found that the framework allows the end user to integrate with the maintenance processes by the help of smart technologies. This integration process can overcome limits of barcode systems and building management systems on localization failure. Koch et al. [9] pointed out that DT in FM is an important factor to commence realizing DT. Moreover, through two case studies, authors showed that the integration of building information modeling (BIM) was not sufficient and that leads to missed opportunities.

Neely [10] defined performance management (PM) as "the process of quantifying the effectiveness and efficiency of an action", and this definition is most often mentioned in the field of business management. In FM, PM can be viewed as a measure of how well FM can identify users' needs and how appropriate the ability to establish regulations to meet these needs and increase productivity [11]. Kristoffersen et al. [12], through an analysis of studies conducted in a number of countries such as Norway, Sweden, Germany and the UK, found that firms with a great potential for business analysis have strong resource orchestration capabilities and a strong ability to excel in the circular economy. In particular, firm capabilities improve the firm's organizational performance in construction, gaining sustainable competitive advantage.

In addition to this, there is currently extensive literature on FM, but there is not a research article that integrates DT in FM and FM PM and systematically analyzes the contribution of the Fourth Industrial Revolution (industry 4.0). In general, our conceptual framework exhibits a novel holistic picture of what has been conducted on DT in FM and FM PM in the last ten years since the industry 4.0. phenomenon began. The analysis of past research literature shows that there is a research gap in analyzing the high transaction cost of applications of digitalization in FM, such as BIM, geographic information system (GIS), Internet of Things (IoT) and so on. The literature review also indicates that there are limited research articles on the methodology development and the development of conceptual framework on cost reduction in DT application in FM. Moreover, this type of limitation is also reflected in the research articles studying knowledge transfers among facility managers in planning, monitoring, evaluation and quality control of facility performance, as well as the analysis of organizational strategic planning of companies dealing with FM. Because there are problems of transferring information and sharing tacit knowledge among users of the building environment, it is suggested that the necessity of a comprehensive study with an adequate theoretical framework is needed.

Therefore, this article contributes to the scientific knowledge body by reviewing the contribution of industry 4.0 and suggesting future research directions, especially with respect to DT in FM and FM PM. Since DT and PM are closely related and core to the field of FM, they are an appropriate context for reviewing this topic. In particular, since DT has been changing over time, we need to pay more attention to the change as a research topic for the field of FM. Furthermore, PM is also an essential element that must be analyzed and incorporated for the systematic development of FM.

The article is structured as follows. First, a systematic literature review is performed to identify articles related to DT and PM with a focus on FM in 39 prominent journals. Next, we analyze the contribution of industry 4.0 for FM based on our research focus. Finally, future research directions are proposed based on the content lacking in the existing literature.

\section{Digitalization (DT) and Performance Measurement (PM) in Facilities Management (FM)}

\subsection{DT in FM}

DT is engineering knowledge which manages the formation of electronic devices, methods and systems that make communication more accurate and flexible. Big data, internet of things, digital twins and block chain are considered as digital technological tools 
in the real estate business. FM has been developing through close connection with high technological progresses in immediate information and flexible communication. When the DT process started in the architecture, engineering and construction (AEC) industry, it was obvious that office design was successively changed. "Today, the technologydriven changes in office work are comparatively small, although the full effects of modern Information and Communications Technology (ICT) on (reduction of) office employment remain to be seen" [13] (p. 370). DT has been supporting FM with its many consequences in practice. From the 2000s, the progress has been seen in the automation system in the construction industry and BIM was partly implemented in it. "The potential for extending the application of major DTs, such as BIM, reality capture technology (including 3D laser scanning, point cloud, photogrammetry), the radio frequency identification (RFID) and GIS, for the purpose of capturing, transferring, and storing big data/information from the design and construction stages through to building operation and maintenance stages, has drawn wide attention." [7] (p. 2). A data management system for asset maintenance that can create data and share information provided by project team members can have a substantial effect on the performance of buildings. In the following sections, the contributions of industry 4.0 applications in FM operations are discussed with case studies.

\subsubsection{BIM}

BIM is the process of information creation and management for buildings throughout design development and operation. The concept of BIM dates back to the 1970s and later in the 2000s, it was successfully used by the Autodesk company. "BIM originated from computer-aided designs using ICT and gradually developed to create BIM models using software tools" [14] (p. 3).

The BIM concept was defined and reviewed in numerous research articles with different perspectives. These research studies indicated the BIM has characteristics such as creation and sharing of the information with different members of a project. BIM was used as an instrument for the enhancement of sustainability of buildings by using energy effectively and maintaining a waste management process in the post-constructed phase in the AEC industry. BIM can be utilized for operations stage functions with the extreme possibility, individually, for operations and maintenance management, energy management, emergency management and quality management, as well as space management [14] Moreover, BIM is seldom implemented in the operation phase, such as redecorations and modifications.

According to Liu and Issa [15], the main purpose of implementing BIM is to create a facility model that is practically relevant to the whole lifecycle of a project. BIM used in the entire lifecycle of a project is a practical experience of generating, maintaining and using building information for dealing with operations and asset maintenance in their entire lifecycle operations [15].

Several researchers have provided practical applications of the tools being implemented in industry 4.0. For instance, Chong et al. [16] defined BIM as one of the crucial cloud computing applications through fragmentation of working practices in the built environment. The explanatory case study has found a number of cloud computing applications, such as BIM, project management and general cloud applications, in various disciplines such as Google Apps, Autodesk BIM 360, Viewpoint, etc. [16] (p. 4). Furthermore, Stojanovic et al. [17] studied advances versus adaptation of industry 4.0 practices in FM. In the case study of the article, authors used Google Tango mobile devices that allow for regular capture and generation of point cloud representations of interior spaces, such as office spaces, conference halls and warehouses. The result showed that the scanned indoor environments acquired using mobile devices can be reconstructed as semantically rich as-is BIM data and as basis data for DTs in FM [17] (p. 7). 


\subsubsection{Geographic Information Systems (GIS)}

Wang et al. [18] defined "GIS are computerized systems based on geography, cartography, and remote sensing technology. They can collect, store, manage, calculate, analyze, display, and describe spatial information and data about the Earth's surface, and they can digitize and visualize abstract information" [18] (p. 2). GIS is a technology that interprets and visualizes data by using maps, reports and charts. Facility managers use GIS technology for disaster planning and response, space management and visualization and so on.

GIS is utilized in various applications, "not only for regional planning, disaster monitoring, agriculture, and infrastructure maintenance, but also for land surveys, cadastral management, environmental management, and other purposes" [18] (p. 2). Furthermore, GIS supports smart sustainable FM because of its potentials in data management, quantitative data analysis and technological applications. In addition, some environmental problems and planning difficulties can also be solved by using GIS models in a more effective and exact way. For instance, GIS models can be used to check the impact of urban designs and construction categories on energy efficiency and carbon emissions in the development of a low-carbon city layout.

In terms of facility surroundings impact analysis, GIS can be the tool for high performance on environmental monitoring, which may visualize and analyze the effect of novel developments or redevelopments on existing facilities or infrastructure and facets of their environments, for example, land use, natural resources, transport and impacted people. Particularly, utilizing Web GIS integrated means more valuable information is gathered from the distributed sources and such information is integrated with BIM data to ease the management of assets/facilities and large-scale urban spaces in reality [18].

Either GIS maps or the integration of GIS and Unmanned Aerial Vehicles (UAVs) are widely used by facility managers in order to provide safety, efficiency of facilities and maintain sustainability. According to Zhang et al. [19] and Sun and Zhang [20], the methodology of a spatial photovoltaic (PV) potential evolution is proposed for structural inspection of the built environment. The method based on the integration of aerial photogrammetry of UAVs and the geographic information system (GIS) can be used not only on roofs of buildings but also built environments such as roads, bridges, car parks, etc. This method is used for outdoor carparks, roads, bridges and the rooftops of buildings in Singapore and Tibet as testing fields. The results showed that the proposed method is applicable to evaluate and inspect efficiency and safety of built environments such as carparks, corridors, reservoirs, roads and horizontal plane [19] (p. 2), [20] (p.16).

\subsubsection{Internet of Things (IoT)}

According to Dahanayake and Sumanarathna [14] (p. 4), "IoT is explained as the network that connects through the internet and stipulates processes through information exchange and communications. IoT has become more relevant with the radical changes in the data and communication industry. Hence, mobile devices and technologies such as data management and cloud systems are significant components in IoT."

The history of the IoT concept dates back to the end of the 1900s. The concept was introduced by the development community of the Radio Frequency Identification (RFID) [21]. The IoT concept has become well-known to the world due to the advancement of technological devices such as mobile phones, computing and analysis of data. The role of IoT applications has recently become relevant to sustainable development management. With the help of the IoT system, the resource transmission of smart cities is improved, environmental pollutants are removed as well as waste management and transport controlling systems are developed. Furthermore, "Data of sensors related to motion, $\mathrm{CO}_{2}$, temperature, airflow, lighting and other acoustics properties are gathered and analyzed by using IoT devices" [9] (p. 4).

Cloud-based IoT tools support smart cities that hold information collected from homes, devices, citizens and so on. "This information is processed and analyzed to monitor 
and manage transportation networks, electric utilities, resources management, water supply systems, waste management, crime detection, security mechanisms, proficiency, digital library, healthcare facilities, and other opportunities" [22] (p. 22). In addition, the implementation of the IoT technologies can help to optimize FM activities including logistics, document management, catalog of historical data, monitoring of asset component lifecycle and asset energy management.

Evjen et al. [23] present the practical implementation of IoT applications in the field of FM. One of them is the indoor positioning system (IPS), which uses smart and non-smart mobile tools such as object tags and beacons. These two devices help positing data and tracking objects that lead to a smart approach in the FM field. St. Olavs Hospital in Norway is used as a case study. As a result, the effectiveness of positioning data collection by IoT devices applied in large and complex buildings can provide an overall view of building status which can improve the efficiency of data application and FM development.

2.1.4. Reality Capture Technology (i.e., Point Cloud, Photogrammetry, and 3D Laser Scanning)

A literature review of research articles related to DT of FM indicated that FM has been evolving with different reality capture technologies, such as automatic identification, laser scanning, point clout and photogrammetry, which can help managers to collect information regarding the operations of a constructed facility. As well, these technologies have enormous contributions to FM because they enable facility managers and engineers to immediately capture end-users' needs and preferences. Xu et al. [24] argued that technologies of reality capturing provide support by creating digital models, monitoring performance and documentation. "Photogrammetry and laser scanning can capture the shape of the historical buildings and facilities, generate a 3D model, and report conditions", and "in some conservation cases, laser scanning and photogrammetry are preferred when identifying the material and evaluating the performance of critical components are necessary, but direct contact and sampling are restricted" [24] (p. 11). According to Hou et al. [25], grounded in the initial implementation of FM operations utilizing the Augmented Visualized Plant Management system (AVPMs), it can be recognized that its system can manage complicated information flows, provide the design placement of electrical components and novel interactive applications for the geo-coordinating navigation and make a concise user interface with exchangeable augmented virtuality (AV), augmented reality (AR) and information modeling (IM) views. Grounded in the methods of usability evaluation, multiple predefined FM scenarios can become utilized as the benchmarks for comparing the efficiency of this system with the conventional FM way. This can be believed so that the FM practitioners can benefit from acquiring a better or best practice solution to the state of the art [25]. The article of Hou et al. [25] demonstrates two case studies such as AV-Supported Pump Maintenance and AR-Supported Remote Input/Output Panel Maintenance based on the Augmented Visualized Plant Management system (AVPMs). The result of the cases showed that the prototype system of AVPMs is advanced, which gives a good opportunity for FM operators to deal with huge amounts of information related to the actual situation and to also connect 3D aligned visual and other feedback to the models of the information system (p. 7).

Cipriani et al. [26] and Wang et al. [27] investigated the production of two different open-source software, such as Visual Source Filmmaker (SFM) and Audio Return Channel (ARC) 3D, on a small-scale but paradigmatic outcrop in the Umbria-Marche Apennines (Italy). The result showed that ARC3D gives a high-resolution model using a fairly short time and demanding an inexpensive hardware support for producing hundreds of photos. Consequently, 3D photogrammetry is proved as being a powerful and effective instrument to digitally maintain and objectively connect significant geological observations. Moreover, 3D photogrammetry promotes accessibility and diffusion of the collected data throughout the scientific group of people [26] (p. 9), [27] (p. 11).

Erdelj et al. [28] and Gallo et al. [29] studied the significant role of UAVs in the structural inspection of facilities. For instance, Erdelj et al. [28] explored an algorithm 
that lets UAVs present an opportunity to provide a structural inspection service that is continuous and uninterrupted. Gallo et al. [29] comprehensively described an example of the integrated usage of UAV photogrammetry and rockfall numerical simulation. Several numerical simulations are used to perform analysis: (1) reproduce the paths followed by the real blocks and (2) estimate the speed and energy of the blocks, together with their heights, impacts and stopping points [28] (p. 8), [29] (p. 5).

\section{2. $P M$ in FM}

In several research works, PM in FM is described in a different way with different measurements. For example, Amos et al. [30] (p. 2) defined in their article that "PM could be viewed as a measure of how adequate FM is at identifying the needs of the users and its ability to put in place proper provisions to satisfy such needs and enhance their productivity." On the other hand, Amaratunga and Baldry [31] described PM as the process of evaluating progress towards obtaining pre-determined goals, which includes information on the efficiency as a way such that resources can be transformed into goods and services, the quality of these outcomes and outputs and the effectiveness of organizational objectives.

Assessing FM performance provides facility managers with clear summary for tactical and strategic FM. Decisions taken by facility managers for the strategy always have a vast impact on the effectiveness of facilities. Furthermore, PM in FM enables asset managers to identify the past and present operational efficiency of a facility and make effective decisions for strategic planning. Koleoso et al. [32] argued that PM refers to the ways to develop the effectiveness of facilities by offering the simple ways of obtaining user requirements with minimum costs and helps the process of resource allocations and re-allocations. Meanwhile, Liyanage and Egbu [33] posited that PM in FM is an efficient tool to discover the positive and negative attributes of the domestic service, assist strategic decision making, work as a reference point to contrast past performance levels with the present ones and identify errors and support with suitable remedies to be undertaken.

The literature review indicated that key performance indicators (KPIs) are mostly used in FM for measuring the performance of a facility as one of the major measurement tools. This is because KPIs can provide facility managers with an accurate analysis to assess the performance of a facility by using appropriate parameters generating from surveys and field studies. In their research work, Amos et al. [30] used a set of KPIs integrated from a maintenance management model to measure maintenance of public care hospital facilities in Israel [30].

\section{Theory and Methodology}

We undertook a systematic literature review to select and analyze research articles published on DT and FM PM from 1990 to 2021. Our focus was placed on the articles published on the subject in the journals of the Academic Journal Guide (AJG) 2021 list of the UK Chartered Association of Business Schools (ABS) (i.e., Automation in Construction, Facilities, Journal of Computing in Civil Engineering, Journal of Construction Engineering and Management, Journal of Engineering, Project and Production Management, Structure and Infrastructure Engineering, Journal of Facility Management, Journal of Performance of Constructed Facilities, Pacific Business Review International and The International Journal of Life Cycle Assessment). The UK ABS produces guidelines to academic journals published within the business and management field and ranks the reputed journals in the field of business and management with a range of $1,2,3,4$ and $4 *$. The higher number indicates the higher ranking.

To create a complete picture, in academic databases, we began to search a wide range of literature articles on the basis of titles, abstracts and keywords, such as "Office of the Future", "Virtual Reality", "Internet of Things", "Smart Buildings", "Circular Economy", "Carbon Footprint", etc. The literature review consists of following two steps. First, abstracts of research articles were roughly scanned and scrutinized to identify whether there was any notion of DT and FM PM involved. Second, all research studies were read in detail. 
Our literature review article integrated two different streams of studies on DT and FM PM. The review of past research on these themes indicated that research articles either on DT in FM or FM PM are separately dealt with. However, in contrast, in our literature review, we try to present a holistic literature review by integrating both research streams on DT applications in FM and FM PM in a single literature review article. This integration makes our study distinctive from other literature review studies. In addition, Table 1 makes our literature review article more like usual literature review studies because it deals with the summary of research contents of the two streams of reviewed studies which gives readers clearer insight into the subject of our literature review article.

Table 1. Summary of research contents.

\begin{tabular}{|c|c|c|}
\hline Author & Year of Publication & Key Findings \\
\hline Adewunmi et al. & 2016 & $\begin{array}{l}\text { The article found that those that perform informal benchmarking find } \\
\text { that the benchmarking tool helps them to improve performance, } \\
\text { service quality and their processes. On the other hand, those that } \\
\text { perform formal benchmarking affirmed that benchmarking helped } \\
\text { them in making strategic plans, striving to be the best in the industry } \\
\text { and obtaining explanations for those improvements that are made now } \\
\text { and in the near future. }\end{array}$ \\
\hline
\end{tabular}

This study explores the role of cloud-based IoT applications in smart

Alam 2021 city development. It is found that, through the help of the IoT system, the resource transmission of cities is improved, environmental pollutants are removed and waste management and transport controlling systems are developed.

Alhamami et al.

Alwan and Gledson

2015

Barletta et al

2016

Barykin et al.

2021

Broniszewski et al.
The results of the study showed that BIM makes a huge contribution to the construction industry of countries in Europe because BIM training and educational projects are implemented to provide European countries with unique energy strategies.

Taking into account the nature of asset management and BIM, a conception model was suggested. It was found that building performance attribute data (BPAD) could be collected within the asset information model (AIM), which could have impact on the delivery of asset management. In addition, the model uses the current building management systems (BMS) and computer aided facility management systems (CAFMs) and points out sustainability strategy issues.

In this article, authors proposed a new methodology framework for assessing and comparing social, economic and environmental impacts occurring from facility changes for electronic waste treatment. This methodology provides important information for decision making and helps to assess the fundamental factors that have impacts on e-waste management systems.

This study indicates that the usage of mathematical modeling associated with systems of differential equations leads to the sustainability of solutions for facility management.

In this study, prospective eco-projects are explored to evaluate energy management of an industry plant. The aim of the projects is to increase the efficiency of energy supply and making the plant independent in heating up facilities.

In this article, digital twins of facility management in the construction field are explored. The article pointed out that digital twins are one of the main integral parts of a software ecosystem deriving from the expectations of AEC/FM practitioners on the BIM role. Furthermore, a digital twin is considered an important source of different independent players to rotate information and produce value for the whole network and provide joint services and products. 
Table 1. Cont.

\begin{tabular}{lll}
\hline Author & Year of Publication & Key Findings \\
\hline & & $\begin{array}{l}\text { This research article proposes a theoretical framework for the } \\
\text { integration of digital technologies in FM. It is found that the framework } \\
\text { allows the end user to integrate with the maintenance processes by the } \\
\text { help of smart technologies. This integration process can overcome the } \\
\text { limitations of barcode systems and building management systems on } \\
\text { localization failure. }\end{array}$ \\
& \multirow{2}{*}{2018} &
\end{tabular}

The study indicated that the usage of wood can decrease the environmental impact in construction, especially during the extraction

Corradini et al. and production phases. Additionally, the wooden material generates low impacts because woods usually originate from forests where there is natural regeneration without any additional chemical inputs such as fertilizers and pesticides.

This research article indicates that the digitalization process can strengthen the connection of products and producers, value chain and consumers to make a sustainable production cycle. Furthermore, the novel technologies could provide firms with opportunities to develop innovations and entrepreneurship as well as improve waste management systems.

The research findings indicated that the integration of BIM and IoT technologies transforms traditional facility management into a digitalized one. These technologies increase the efficiency of building

Dahanayake and

Sumanarathna

Deng et al. 2021

Eisen et al.

Elwood 2008

Fortino and Guerrieri

Ginthotavidana and Waidyasekara management. The applications of BIM-IoT technologies can be effectively integrated into six asset management functions such as energy management, operations and maintenance management, space management, FM project management, emergency management and quality management.

There are a number of prior studies conducted thus far that have not fully implemented or realized the envisioned concept of the digital twin and are, therefore, categorized under the earlier ladder classifications.

It is found that the rational utilization of digital smart tools leads to progressive growth in process and safety. Smart laboratories are described as pave the way for the flexible prospective process. In contrast, digitalization-oriented knowledge management will make a big contribution to rapid process and product development.

This article investigates the early literature on "volunteered geographic information" (VGI), describing its shared propositions. So, these new technologies are part of shifts in the social and technological processes through which digital spatial data are produced.

In this article, an agent-oriented decentralized and embedded architecture based on wireless sensor and actuator networks (WSANs) is suggested in order to achieve efficient and effective asset management. Higher level application specific agents can easily adapt due to the high flexibility of the agent-oriented architecture. This easy adaptation allows the agents to use the architecture for realization of the asset management policies.

Customer PMs are important when measuring the HK service performance in health-care environments. The interviewees of all three cases stated that patient satisfaction level, service quality level and the number of HK-related complaints are important KPIs for HK PM. 
Table 1. Cont.

\begin{tabular}{lll}
\hline Author & Year of Publication & Key Findings \\
\hline & & $\begin{array}{l}\text { This article indicated that there is a need for the enhancement of } \\
\text { practices in cross-sectional projects. In order to implement such } \\
\text { practices, there is a need for integrated information and the } \\
\text { management of digital technology as well as exploitation of existing } \\
\text { technologies in cross-sectional connection with the variety of processes } \\
\text { and information during all of the lifecycle. }\end{array}$ \\
\hline
\end{tabular}

Hou et al.

Ilter and Ergen

2015

Jayasena and

Mallawaarachchi

2019

Kassem et al.

2015

Koch et al.

2019

Kortuem et al.

2010

Kristoffersen et al.

2021

Lin et al.

2013
Jurado et al.

It is found that this article focuses on the method for the technological realization of the system. With the successful enhancement of the system, it can cope with the management of complex information flows, support the users' navigation in geo-coordinates and make a smart IM interface with switchable AV/AR scenes.

In this article, the results showed that studies related to BIM applications in maintenance are relatively recent. However, the trend in published articles indicates that the interest is continuously growing.

In this research study, a model to assess and formulate the status of environmental sustainability of FM in the apparel industry in Sri Lanka has been developed. According to the assessment model, energy management was found as the most important FM function regarding environmental sustainability in the industry.

The article proposes a conceptual framework that shows smartphone potentials to catch important features of user environment and demonstrates the hidden facilities by different realities. Moreover, the results pointed out the capability of the application to cope with the status and control the management of indoor facilities only using systems.

The value of BIM in FM comes from improvement to information transmission manual process, advancement of FM data accuracy, improvement of FM data accessibility and efficiency increase in the performance of the work order. In terms of challenges, there are a lack of methodologies and the knowledge of implementation requirements are limited, and there is shortage of BIM skills in FM.

The article pointed out that the integration of technological

digitalization, capabilities, organization and management of FM digitalization are important factors to commence realizing digitalization. In addition, the two cases showed that the integration of BIM was not sufficient so that opportunities are missed.

In this study, authors explored the architecture's hierarchy focusing on a high level of awareness and real-world interactivity. They outlined the activity-, policy-, and process-aware smart buildings and showed how to support complex application by architectural abstractions.

It is found that firms with a great potential for a business analysis have strong resource orchestration capabilities and a strong ability to excel in the circular economy. The firm's capabilities improve firm organizational performance in construction, gaining sustainable competitive advantage.

It is found that BIM technology plays a significant role to enhance FM work. FM managers can effectively control and track the asset management process throughout the integration of BIM and 2D barcode technologies.

Lindkvist et al.

2021
The article fills the gap in urban development, especially in smart city planning through connecting neighborhoods and connectivity using innovative approaches of optimizing data and good governance of FM. 
Table 1. Cont.

\begin{tabular}{|c|c|c|}
\hline Author & Year of Publication & Key Findings \\
\hline Liu and Issa & 2016 & $\begin{array}{l}\text { This study suggests that knowledge should be accumulated and shared } \\
\text { through the project lifecycle for BIM-FM. The result indicated that there } \\
\text { is a need to focus on the maintainability issues in the design and } \\
\text { construction phases. It would be an initial point for a BIM-FM } \\
\text { knowledge sharing database. Moreover, results showed that there is a } \\
\text { need for better practices and technologies, such as the D4M rules, to } \\
\text { prevent maintainability problems in phases of design and construction. }\end{array}$ \\
\hline Madarász & 2011 & $\begin{array}{l}\text { It is found that the methodology presented in this research work is } \\
\text { applicable for benchmarking of facility maintenance management. The } \\
\text { results clearly support the need to conduct a similar survey among } \\
\text { other types of organizations to determine whether the criteria for good } \\
\text { practice are similar to those of higher education institutions and } \\
\text { whether the model can be applied to other types of organizations. }\end{array}$ \\
\hline
\end{tabular}

The result indicated that the integration of end users in the process of maintenance can reduce the existing barcode system limits by using smart tools. It can also overcome the limits of building management systems for localization failure. Moreover, the research framework suggests a number of advantages. For instance, it can give an opportunity to identify every element of building. In addition, a whole management activity is controlled through a special integrated system.

This article describes that, in the development of smart cities, the Arrowhead framework shows its efficiency in utility system and energy Marcu et al. consumption. In smart agriculture, there is a need for a big primary investment, effective farming equipment and experienced and skillful farmers. A lack of knowledgeable farmers is a potential challenge in the smart agriculture development.

The result of the article pointed out that sustainability plays a

Marzouk et al.

2021 significant role in the digitalization of construction filed under BIM frameworks. In addition, the framework of effective decision making helps address sustainability issues and alleviate the negative effects of the construction sector.

Various IT systems are usually used for managing environmental building performance (EBP). EBP is mainly reflected in energy management, with strong emphasis on controlling and reporting Maslesa and Jensen 2019 heating, water and electricity consumption. Moreover, in some IT systems, greenhouse gas emissions generated from energy consumption can be calculated, whilst other building materials and recycling potentials are not appropriately maintained by the IT systems mentioned in this study.

In this article, authors argued that in the public sector, ESCO

Nardelli et al. collaborations are characterized in and of themselves as innovation processes, becuase they result in outcomes such as new processes for energy monitoring.

This article covers two characteristics of Future IoT architecture: Unit IoT and Ubiquitous IoT. Unit IoT architecture is constructed by the model of man such as neural network (MLN) and its adjusted model. Ubiquitous IoT architecture is built from the global IoT or the combination of several Unit IoTs with the "ubiquitous" model, and its structure utilizes the model of social organization framework (SOF).

The research findings showed that huge benefits can be gained from using cloud computing in the construction industry of Nigeria. There are great benefits of cloud computing to construction projects from different angles, such as IT applications, constructive planning and collaboration among partners. 
Table 1. Cont.

\begin{tabular}{lll}
\hline Author & Year of Publication & Key Findings \\
\hline Oyedeji & $\begin{array}{l}\text { This study showed that the hard facility management services have } \\
\text { direct influence on the main university functions such as research and } \\
\text { teaching. Meanwhile, soft facility management services are relevant for } \\
\text { the smooth operation of the university. }\end{array}$ \\
& $\begin{array}{l}\text { In this research work, the result of the tested hypothesis showed that } \\
\text { the concepts of sustainability and green management is the attainable } \\
\text { solution to unsatisfactory states of facilities. Moreover, the result } \\
\text { pointed out that all stakeholders, such as facility managers and users, } \\
\text { building experts, policy makers, environmentalists, etc., play a vital } \\
\text { role to overcome barriers, realization of projects and performance } \\
\text { management. }\end{array}$ \\
\hline \multirow{2}{*}{2019} & \\
&
\end{tabular}
management.

Palander and Takkinen

2021

Pavón et al.

2021

Pavón et al. 2020

This article explores that, in order to achieve a carbon-neutral supply chain, strategic energy reforms that also help to enhance energy efficiency should be conducted. Furthermore, the supply of cost and energy effective wood can increase the competitiveness of the region's municipality specificity.

It is found that utilizing a three-dimensional information model connected with other applications, databases and other asset management tools can transform large conventional public buildings into efficient and smart sustainable buildings.

The implementation of a BIM based FM system for the Civil Engineering School improved the facility management of the school. For example, it provides the possibility of making any reservations, setting academic scheduling, providing temperature and humidity, revealing setting capacity, etc.

In this study, some new technologies such as 3D mapping, indoor positioning system (IPS), Motion Capture System (MoCap) and Immersive Reality (IR) are used. Using these technologies helps to reconfigure the structure that has a positive impact on the three pillars of sustainability concepts. As a result, the incurring costs are reduced and environmental and social challenges are mitigated.

This article presents how to use BIM for energy efficiency in buildings in the operation phase, with the aim of achieving carbon emissions.

Petri et al.

2017 Furthermore, two contributions were suggested which are the BIM-oriented methodology on energy optimization of buildings and a case study of European research project "Sporte2" to indicate the advantages of BIM in energy efficiency.

Pitt et al.

2006

Authors of the article found that innovativ issues a the maintenance issues are important for constant efficiency and are generated through the creation of an environment where creativity is able to develop.

This study analyzes the shortcomings of previous approaches in using GIS in renewable energy-related projects, extracts distinct challenges from these previous efforts and, finally, defines a set of core future research avenues for GIS-based energy infrastructure planning with a focus on the use of renewable energy.

This research work makes a big contribution to the understanding of digital tools in the development of smart city governance. Moreover, Rönkkö and Herneoja 2021 the article pointed out a great coordinative potential of digital boundary objects in inter-sectoral planning issues by enriching the transformation, transfer and translation of knowledge.

It is found that using applications of smart technologies in underground space construction helps to construct a comprehensive system that uses digital technology and collects data from the whole lifecycle of underground facilities for their optimal management safety.
Shahrour et al. 
Table 1. Cont.

\begin{tabular}{ll}
\hline Author & Year o \\
\hline Temidayo et al. & 2020
\end{tabular}

Key Findings

It is found that there is a high need for the development of smart buildings as a tool to prevent coronavirus dispersion. Maintenance cost, occupant's behavior and maintenance strategy are considered as the main challenges for maintenance management of smart buildings.

In this article, it is found that the facility managers should act as integrators in the process of maintaining sustainable FM. To integrate

Tiwari and Panicker sustainable practices with the desire of an organization, and to achieve cost-effective facility management, the green and sustainability need to be integrated into the organization's overall strategy.

In this study, the findings indicated that the dashboard framework of IoT-BIM integration and the preventive maintenance methodology of

Villa et al.

2021 used building structures are relevant and favorable. Because of the analysis and $3 \mathrm{D}$ visualization to help the indoor condition monitoring in facilities, facility managers can make faster and better decisions on improving real time monitoring of building facilities.

\section{Wang et al.}

2012

In this article, a smart multiagent control system is designed, and the potential of acquiring the main goals through integrating the multiple agents and the optimizer was indicated.

\section{Xu et al.}

2020

Yalcinkaya and Singh

2018

Yan et al.

2021

Zhang et al.
2017
Authors found that applications of PSTs and FM configure a many-to-many 13 mapping, i.e., one PST could promote many FM applications, and one application can also be 14 supported by various PSTs.

In this work, the theory of Gestalt's principles of visual perception is used. This theory provided an applicable and implementable cornerstone for improving the applicability and relevance of COBie spreadsheets. The BIM-integrated, graph-based VisualCOBie platform provides visual navigation and advanced search as well as decreasing the rational load of large spreadsheets that are used often in FM software.

This article proposes the assessment framework of lifecycle economic and carbon emissions through dividing the system into five stages. A multi-objective mathematical model is also developed throughout the case study on the building energy system design. As a result, it is found that the carbon footprint in the operation and maintenance stage of building is responsible for two-thirds of share in the entire lifecycle.

This article investigates BIM-based methodologies for pre-construction design, verification and post-construction facility management of smart buildings in the smart grid era. Prototype of a smart house energy management system using Revit and the xBIM toolkit was also implemented and successfully demonstrated.

This study explores an algorithm that lets UAVs (Unmanned Aerial Vehicles) present an opportunity to provide structural inspection service that is continuous and uninterrupted. The implementation of the algorithm is ensured with MAVLink protocol.

This article proposes to review the-state-of-the-art methods to obtain and activate 3D point cloud data for construction management applications. Authors reviewed different approaches of 3D point cloud data acquisition. 
Table 1. Cont.

\begin{tabular}{|c|c|c|}
\hline Author & Year of Publication & Key Findings \\
\hline Yan et al. & 2014 & $\begin{array}{l}\text { Authors proposed a method that uses digital technologies such as GIS } \\
\text { and remote sensing, photogrammetry and Moderate Resolution } \\
\text { Imaging Spectroradiometer (MODIS) for structural inspection of Three } \\
\text { Gorges Dam in Dongting Lake in China, and for extracting a record of } \\
\text { the lake's bottom topography from } 2003 \text { to } 2011 \text {. The result indicated } \\
\text { that the lake's bottom topography has showed uneven erosion and } \\
\text { downfall regarding time and space over the last nine years }\end{array}$ \\
\hline Zhang et al. & 2019 & $\begin{array}{l}\text { In this article, the method of spatial photovoltaic (PV) potential } \\
\text { evaluation which, on the basis of the integration of aerial } \\
\text { photogrammetry and geographic information system (GIS), is } \\
\text { proposed for PV potential evaluation of built environment (BE). This } \\
\text { method can be applied to PV potential evaluation of not only building } \\
\text { roofs but also built environments such as carparks. }\end{array}$ \\
\hline Sun et al. & 2018 & $\begin{array}{l}\text { In this study, authors used the case study of Tibet in the usage of } \\
\text { "Drones and 3D Modeling to Survey Tibetan Architectural Heritage: A } \\
\text { Case Study with the Multi-Door Stupa". The results of the survey } \\
\text { showed that the UAV-derived model is accurate enough for most } \\
\text { surveying purposes. }\end{array}$ \\
\hline
\end{tabular}

Authors of this article comprehensively described an example of the integrated usage of UAV photogrammetry and rockfall numerical

Gallo et al. $\quad 2021$ simulation. Several numerical simulations are used to perform analysis: (1) reproduce the paths followed by the real blocks and (2) estimate the speed and energy of the blocks, together with their heights, impacts and stopping points.

The authors studied advances versus adaptation of industry 4.0 practices in FM. In a case study of the article, they used Google Tango mobile devices which allow for regular capture and generation of point Stojanovich et al. cloud representations of interior spaces, such as office spaces, conference halls and warehouses. The result showed that the scanned indoor environments acquired using mobile devices can be reconstructed as semantically rich as-is BIM data and as basis data for DTs in FM.

Authors investigated BIM as one of the crucial cloud computing applications through fragmentation of working practices in the built environment. The explanatory case study has found a number of cloud computing applications, such as BIM, project management and general cloud applications, in various disciplines such as Google Apps, Autodesk BIM 360, Viewpoint, etc.

In their article, authors present practical usage of an IoT application, which is the indoor positioning system (IPS), that utilizes smart and non-smart mobile devices such as object tags and beacons in order to posit data and track objects that lead to a smart approach in the FM

Evjen et al. field. St. Olavs Hospital in Norway is used as a case study. As a result, the effectiveness of positioning data collection by IoT devices applied in large and complex buildings can provide an overall view of building status which can improve the efficiency of data application and FM development. 
Table 1. Cont.

\begin{tabular}{|c|c|c|}
\hline Author & Year of Publication & Key Findings \\
\hline Cipriani et al. & 2016 & $\begin{array}{l}\text { In this study, authors investigated the production of two different } \\
\text { open-source software, such as Visual Source Filmmaker (SFM) and } \\
\text { Audio Return Channel (ARC) 3D, on a small-scale but paradigmatic } \\
\text { outcrop in the Umbria-Marche Apennines (Italy). The result showed } \\
\text { that ARC3D gives a high resolution model, using a fairly short time } \\
\text { and demanding an inexpensive hardware support for producing } \\
\text { hundreds of photos. Consequently, 3D photogrammetry is proved as } \\
\text { being a powerful and effective instrument to digitally maintain and } \\
\text { objectively connect significant geological observations. Moreover, 3D } \\
\text { photogrammetry promotes accessibility and diffusion of the collected } \\
\text { data throughout the scientific group of people. }\end{array}$ \\
\hline
\end{tabular}

Meng et al.

2011

Pathirage

Bean

Becerik-Gerber

2012
Authors mentioned that a balanced scorecard (BSC) can balance the inside and outside of an organization, and emphasized the importance of effective organizational management using effective organizational PM tools.

Authors argued that the studies on the knowledge management were related to intellectual capital divided into human capital, structural capital and customer capital, and they divided a maturity model of knowledge management in FM into four stages: (1) recognition of importance, (2) formulation of strategy, (3) implementation of techniques and (4) evaluation of performance.

Bean et al. argued that BIM technology can be helpful to solve problems associated with costs of projects. Facility managers always pay attention to the costs coming from the earlier phases of construction projects.

Becerik-Gerber et al. indicated that one of the important tasks of facility managers and stakeholders is to reduce the total facility-related costs in operation and maintenance costs deriving from design and craftsmanship of building.

Liyanage and Egbu posited that PM in FM is an efficient tool to discover the positive and negative attributes of the domestic service, assist strategic decision making, work as a reference point to contrast past performance levels with the present ones and identify errors and support with suitable remedies to be undertaken.

\subsection{Analysis of Past Research}

Through data collection and selection, in this study, a broader variety of research journals were scanned, reviewed and considered to obtain as many research articles as possible, because DT and FM PM is a new area of study. Avoiding the limitations on the implementation of a sole search engine, we used two search engines, i.e., Web of Science and Google Scholars, because they are more helpful tools to obtain a wide range of multidisciplinary scholarly articles in the field. As a result, 130 articles published between 1990 and 2021 in high-ranking academic journals were identified and only 61 articles were cited, as the remaining studies were not (directly) relevant to our review article's subject.

Our study's organizational framework for review encompasses analyzing the abovementioned articles. The reviewing process consisted of several stages with the participation of all authors. In the first step, we coded the journal, year, country, theoretical lens and research focus for each study on the basis of the title, abstract, keywords and content of each article. In the second step, all these workflows were reviewed and the coding checked. In case there were inconsistencies, we discussed and provided relevant solutions to them. Finally, based on this coding, a conceptual framework of this review article was created to integrate the research themes. 
Figure 1 illustrates a conceptual framework of three research themes we identified through our literature review. The figure indicated that there is a one-sided causal relationship among DT applications, and PM and FM components, and their relationship with components of sustainability. In general, the figure presents a novel holistic picture of what has been conducted on DT in FM and FM PM in the last ten years after the industry 4.0 revolution began. Furthermore, it also identifies research limitations on the themes and helps us to present new future research directions. Our analysis of past research literature shows that there is a research gap in analyzing the high transaction cost of DT applications in FM, such as BIM, GIS, IoT and so on. The literature review also indicates that there are limited research articles concerning the methodology development and the development of a conceptual framework on cost reduction in DT applications in FM. Furthermore, these kinds of limitations are also reflected in the research articles studying knowledge transfers among facility managers in planning, monitoring, evaluating and quality control of facility performance. Moreover, the research gap is found in the analysis of organizational strategic planning of companies dealing with FM. Because of the barriers of transferring and sharing tacit knowledge and information among users of building environment, there is a need for comprehensive research with an adequate theoretical framework.

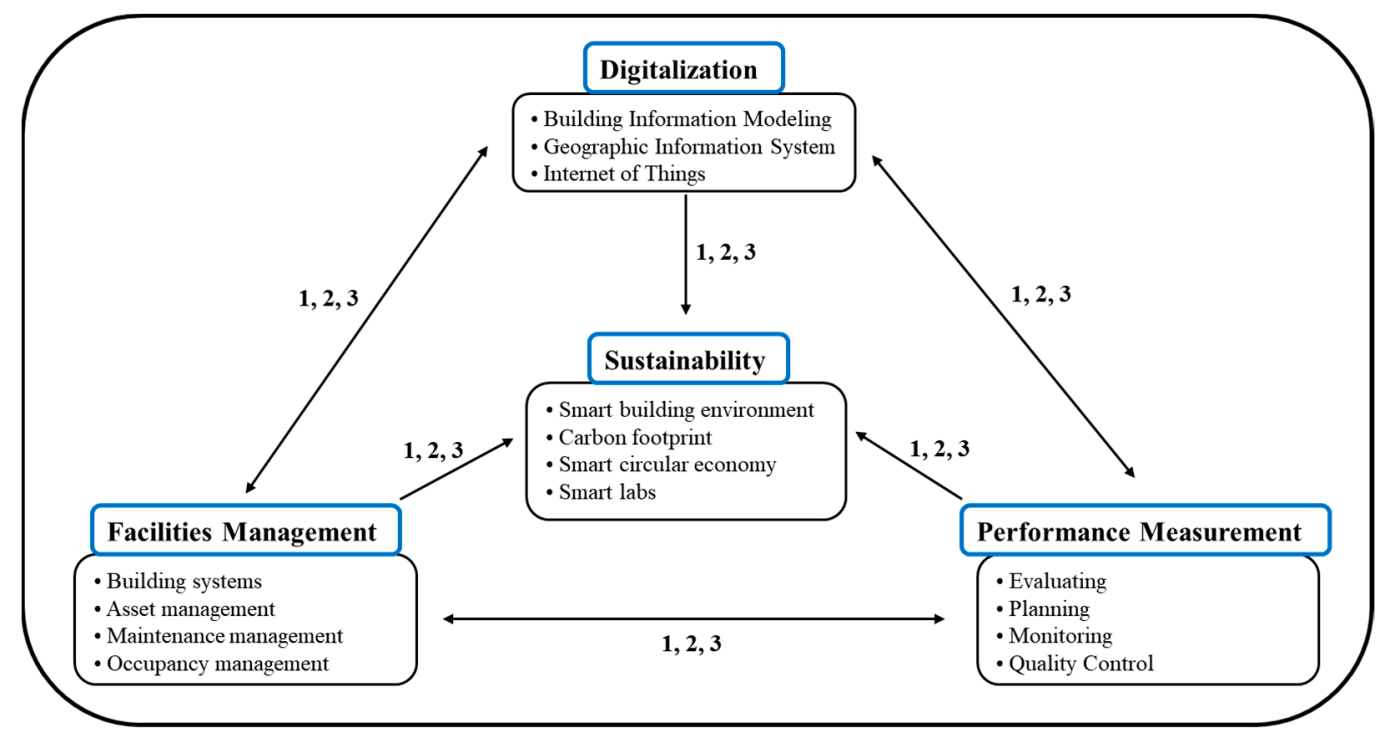

Figure 1. Conceptual framework. Notes: This figure shows the relationship between each component. (1) Transaction cost theory (a cost analysis); (2) knowledge-based view (an analysis of knowledge transfer); (3) organizational theory (an analysis of organizational strategic planning).

Out of the summary of Figure 1, it is concluded that the theoretical contribution of our article is to organize systematizing academic studies with theoretical developments because there is a limited number of theories that have been used in the research articles concerning DT in FM and PM FM, and the past literature review analysis showed that most used theories are knowledge-based view, organizational theory and transaction cost theory.

Figure 2 and Table 2 indicate the classification of articles based on journals and time periods. The table proves an increasing tendency regarding the number of published articles on this subject over time. As the table shows, Facilities and Energies have published many articles on DT and FM PM, with the exception of Sustainability, which has published four articles on this topic. Next, we classified the articles into various categories based on the country distribution of articles in Figure 3 and Table 3. As it is shown in Table 3, the UK is among the most frequently (7 times) employed as a sample country, whilst Finland and Italy are less used compared to the UK (6 times). In addition, Nigeria and Norway are used 5 times as sample nations in the literature review articles on the topic. As a conclusion, Figure 3 and Table 3 provide us with the information that, among the reviewed articles, the majority of studies has been conducted in Western European nations. 
Our literature review analysis showed that there have been no literature review studies on DT in FM and FM PM that have reviewed country distributions of FM samples. It is one of the contributions of our review work, which can help to obtain a clearer understanding of the topic. Furthermore, it can be an important direction for future researchers of FM study, because the country distribution of review articles provides researchers with information about what continents there is a need for more research studies in the FM field or which countries there have not been studied yet regarding DT in FM and FM PM.

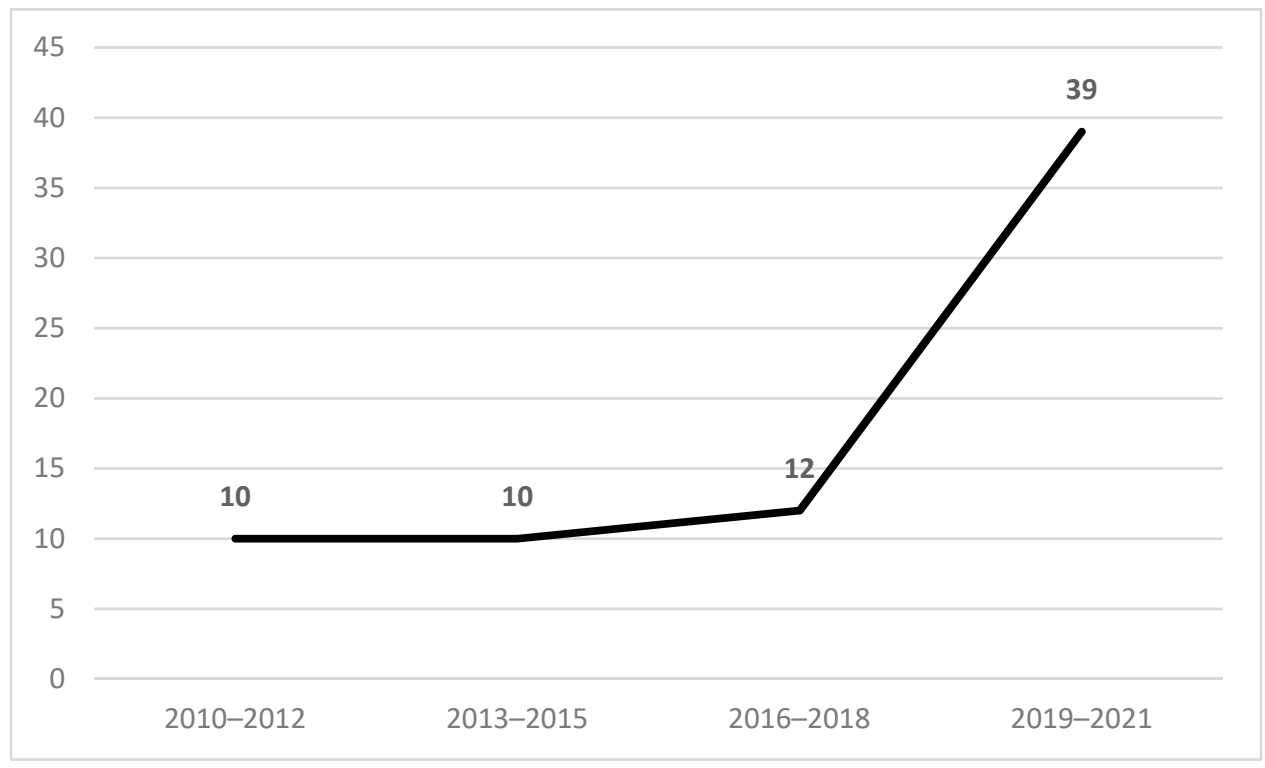

Figure 2. Number of journals in which the reviewed articles were published.

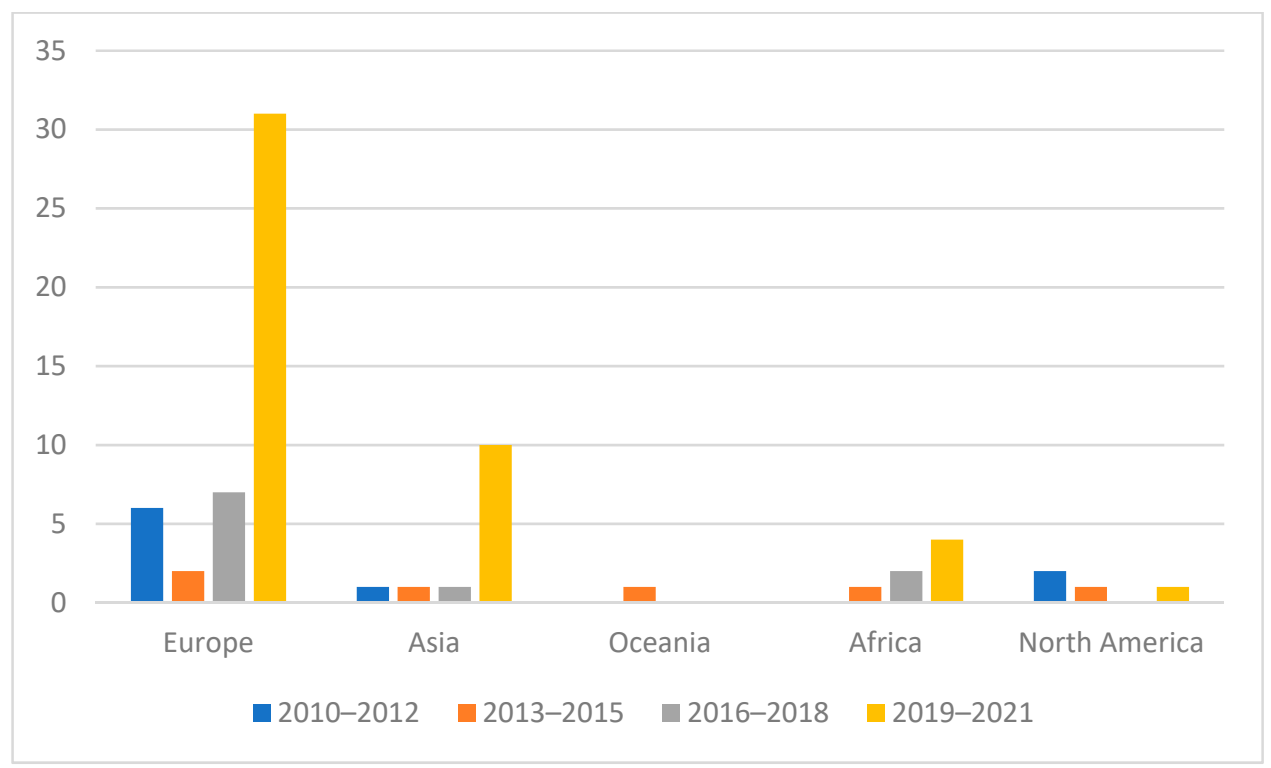

Figure 3. Continent distribution of articles on Digitalization in FM and FM PM: Contribution of industry 4.0 . 
Table 2. Distribution of publications by journals and years.

\begin{tabular}{|c|c|c|c|c|c|}
\hline Journal & 2010-2012 & 2013-2015 & 2016-2018 & 2019-2021 & Total \\
\hline Acta Polytechnica Hungarica & 1 & 0 & 0 & 0 & 1 \\
\hline Ad Hoc Networks & 0 & 0 & 1 & 0 & 1 \\
\hline Analytical and Bioanalytical Chemistry & 0 & 0 & 0 & 1 & 1 \\
\hline Applied Science-Basel & 0 & 0 & 0 & 3 & 3 \\
\hline Archives of Computational Methods in Engineering & 0 & 0 & 0 & 1 & 1 \\
\hline Automation in Construction & 0 & 1 & 0 & 1 & 2 \\
\hline Buildings & 0 & 1 & 0 & 0 & 1 \\
\hline Built Environment Project and Asset Management & 0 & 1 & 0 & 1 & 2 \\
\hline Built Environment Project and Asset Management & 0 & 2 & 0 & 1 & 3 \\
\hline Construction Innovation & 0 & 0 & 0 & 1 & 1 \\
\hline Computer Science and Information System & 1 & 0 & 0 & 0 & 1 \\
\hline Ecological Chemistry and Engineering & 0 & 0 & 0 & 1 & 1 \\
\hline Energies & 0 & 1 & 1 & 4 & 6 \\
\hline Energy Science E Engineering & 0 & 0 & 0 & 2 & 2 \\
\hline Facilities & 2 & 1 & 3 & 3 & 9 \\
\hline IEEE ACCESS & 0 & 0 & 0 & 2 & 2 \\
\hline IEEE Communications Letters & 1 & 0 & 0 & 0 & 1 \\
\hline IEEE Internet Computing & 1 & 0 & 0 & 0 & 1 \\
\hline IEEE Transactions on Smart Grid & 1 & 0 & 0 & 0 & 1 \\
\hline International Journal of Built Environment and Sustainability & 0 & 0 & 1 & 0 & 1 \\
\hline International Journal of Construction Management & 0 & 0 & 0 & 1 & 1 \\
\hline International Journal of Geo-Information & 0 & 0 & 1 & 0 & 1 \\
\hline International Journal of Production Economics & 0 & 0 & 0 & 1 & 1 \\
\hline Italian Journalof Geosciences & 0 & 0 & 1 & 0 & 1 \\
\hline Journal of Cleaner Production & 0 & 0 & 0 & 1 & 1 \\
\hline Journal of Construction Engineering and Management & 2 & 0 & 0 & 0 & 2 \\
\hline Journal of Engineering, Design and Technology & 0 & 0 & 0 & 2 & 2 \\
\hline Journal of Facilities Management & 1 & 0 & 0 & 1 & 2 \\
\hline Journal of Information Technology in Construction & 0 & 0 & 0 & 1 & 1 \\
\hline Journal of Performance of Constructed Facilities & 0 & 1 & 0 & 0 & 1 \\
\hline Management & 0 & 0 & 1 & 0 & 1 \\
\hline Real Estate Management and Valuation & 0 & 0 & 0 & 1 & 1 \\
\hline Remote Sensing & 0 & 0 & 0 & 1 & 1 \\
\hline Scientific World Journal & 0 & 2 & 0 & 0 & 2 \\
\hline Sensors & 0 & 0 & 0 & 2 & 2 \\
\hline Smart Cities & 0 & 0 & 0 & 3 & 3 \\
\hline Sustainability & 0 & 0 & 2 & 3 & 5 \\
\hline The International Journal of Life Cycle Assessment & 0 & 0 & 1 & 0 & 1 \\
\hline Underground Space & 0 & 0 & 0 & 1 & 1 \\
\hline Total & 10 & 10 & 12 & 39 & 71 \\
\hline
\end{tabular}


Table 3. Country distribution of articles on Digitalization in FM and FM PM: Contribution of industry 4.0 .

\begin{tabular}{|c|c|c|c|c|c|}
\hline Sample Country & 2010-2012 & 2013-2015 & 2016-2018 & 2019-2021 & Total \\
\hline Austria & 0 & 0 & 0 & 1 & 1 \\
\hline China & 1 & 0 & 1 & 3 & 5 \\
\hline Denmark & 0 & 0 & 0 & 1 & 1 \\
\hline Egypt & 0 & 0 & 0 & 1 & 1 \\
\hline Finland & 0 & 0 & 1 & 5 & 6 \\
\hline France & 0 & 0 & 1 & 1 & 2 \\
\hline Germany & 0 & 0 & 0 & 2 & 2 \\
\hline Greece & 0 & 0 & 0 & 1 & 1 \\
\hline Hong Kong & 0 & 0 & 0 & 1 & 1 \\
\hline Hungary & 1 & 0 & 0 & 0 & 1 \\
\hline India & 0 & 0 & 1 & 1 & 2 \\
\hline Italy & 1 & 0 & 3 & 2 & 6 \\
\hline Korea & 0 & 0 & 0 & 0 & 0 \\
\hline New Zealand & 0 & 1 & 0 & 0 & 1 \\
\hline Nigeria & 0 & 1 & 2 & 2 & 5 \\
\hline Norway & 0 & 0 & 0 & 5 & 5 \\
\hline Malaysia & 0 & 0 & 0 & 1 & 1 \\
\hline Poland & 0 & 0 & 0 & 1 & 1 \\
\hline Romania & 0 & 0 & 0 & 1 & 1 \\
\hline Russia & 0 & 0 & 0 & 1 & 1 \\
\hline Saudi Arabia & 0 & 0 & 0 & 1 & 1 \\
\hline Scotland & 1 & 0 & 0 & 0 & 1 \\
\hline Singapore & 0 & 0 & 0 & 1 & 1 \\
\hline South Africa & 0 & 0 & 0 & 1 & 1 \\
\hline Spain & 0 & 0 & 0 & 4 & 4 \\
\hline Sri Lanka & 0 & 0 & 0 & 2 & 2 \\
\hline Sweden & 0 & 0 & 1 & 2 & 3 \\
\hline Taiwan & 0 & 1 & 0 & 0 & 1 \\
\hline UK & 3 & 2 & 0 & 4 & 9 \\
\hline USA & 2 & 1 & 0 & 1 & 4 \\
\hline Total & 9 & 6 & 10 & 46 & 71 \\
\hline
\end{tabular}

Table 4 exhibits a wide range of the research focuses of the articles reviewed in our study. The value of the table is that it helps to obtain a clearer insight into the range of our review article's topic by presenting additional knowledge. As it is shown in the table, the majority of the reviewed articles' research focus is DT in FM, which is followed by innovation and digitalization in FM and sustainability in FM. Furthermore, Table 5 demonstrates that knowledge-based, organizational and transaction cost theories are among the most frequently employed ones in the research on DT and FM PM articles. Other theories used in this area include agency theory, network theory, the theory of lifecycle assessment and so on. In addition, it should be indicated that most of the research articles are theory-free or implicit theory-based studies in this literature review. We can conclude from Table 5 that there is a need for more systematic research efforts on theory and methodology developments. Therefore, we propose that it will be prosperous in future directions for researchers on facility management field. Below, the major theories used in this article are discussed and their relevance to the studies are examined. 
Table 4. Research focus of articles on Digitalization in FM and FM PM: Contribution of industry 4.0.

\begin{tabular}{|c|c|c|c|c|c|}
\hline Topic & 2010-2012 & 2013-2015 & $2016-2018$ & 2019-2021 & Total \\
\hline Benchmarking & 0 & 1 & 1 & 0 & 2 \\
\hline Benchmarking-PM & 1 & 0 & 1 & 0 & 2 \\
\hline Benchmarking and innovation & 0 & 0 & 1 & 1 & 2 \\
\hline BIM-PM-sustainability & 1 & 0 & 1 & 0 & 2 \\
\hline $\mathrm{BIM}$ in FM & 0 & 1 & 1 & 1 & 3 \\
\hline BIM in hard FM & 0 & 1 & 0 & 0 & 1 \\
\hline BIM-GIS integration & 0 & 0 & 1 & 1 & 2 \\
\hline BIM-IoT integration-FM & 0 & 0 & 1 & 0 & 1 \\
\hline Digitalization and sustainable development & 0 & 0 & 0 & 1 & 1 \\
\hline Digitalization in FM & 7 & 1 & 0 & 7 & 15 \\
\hline Digitalization in sustainable FM & 0 & 0 & 1 & 2 & 3 \\
\hline Environmental sustainability in FM & 0 & 0 & 0 & 2 & 2 \\
\hline FM-2D-BIM & 0 & 1 & 0 & 0 & 1 \\
\hline FM-innovation-benchmarking & 0 & 0 & 0 & 1 & 1 \\
\hline FM-soft and hard FM & 0 & 1 & 1 & 1 & 3 \\
\hline FM & 1 & 1 & 0 & 1 & 3 \\
\hline GIS in FM & 0 & 0 & 1 & 0 & 1 \\
\hline Industry 4.0 in FM & 0 & 0 & 0 & 1 & 1 \\
\hline Innovation and digitalization in FM & 0 & 0 & 1 & 3 & 4 \\
\hline Innovation and sustainability in FM & 0 & 0 & 0 & 1 & 1 \\
\hline $\mathrm{PM}$ & 2 & 0 & 0 & 2 & 4 \\
\hline $\mathrm{PM}$ and BIM in FM & 0 & 0 & 0 & 1 & 1 \\
\hline PM and DT in FM & 0 & 0 & 0 & 2 & 2 \\
\hline Sustainability and digitalization & 0 & 0 & 0 & 1 & 1 \\
\hline Sustainability-FM & 0 & 0 & 1 & 3 & 4 \\
\hline UAVs (Unmanned Aerial Vehicles) & 0 & 0 & 3 & 2 & 5 \\
\hline 3D Point Cloud in FM & 0 & 0 & 1 & 1 & 2 \\
\hline Others & 0 & 0 & 0 & 1 & 1 \\
\hline Total & 12 & 7 & 16 & 36 & 71 \\
\hline
\end{tabular}

\subsection{Theories in the Research of DT and PM in FM}

\subsubsection{Knowledge-Based View}

Knowledge-based view (KBV) is considered a strategic management theory that is usually used in FM literature during the last decade. Therefore, the information used in the construction industry should be correct, reliable and pervasive to maintain efficiency in FM. Moreover, digital technologies, such as BIM, IoT, GIS, etc., are valuable resources and their software outputs make them differ in the construction market. In addition, the outputs produced by the DT applications are considered a vital resource for companies in the construction industry. However, Maslesa and Jensen [34] (p. 3) considered that "the FM sector continues to struggle with information management, mostly due to the peculiarity of information and its fragmentation" and "IT systems are, therefore, needed to manage and consolidate the data and information necessary to make decisions about how to operate and maintain buildings".

Pathirage et al. [35] (p. 4) argued that "the studies on the knowledge management was related to intellectual capital divided into human capital, structural capital and customer capital" and they "divided a maturity model of knowledge management in FM into four stages: (1) recognition of importance; (2) formulation of strategy; (3) implementation of techniques; and (4) evaluation of performance".

Liu et al. [15] suggested that knowledge can be accumulated and shared through the project lifecycle for BIM-FM. Their finding indicated that it is necessary to concentrate on the maintainability agendas in the design and construction phases. It could be an initial point for a BIM-FM knowledge sharing database. In addition, their findings showed that there is a need for better practices and technologies such as the D4M rules to hinder the maintainability problems in the phases of design and construction [15]. 
Acquiring and combining different kinds of information can evaluate and measure facility performance, environmental influence, operative costs and so on. Asset managers should have a relevant information system and data sets for supporting their decisions. Maslesa and Jensen [34] argued that, nowadays, in FM literature, information communication technologies can be divided into seven categories. Two of them are workflow systems and facilities intelligence systems directly associated with the ICT system. The other categories deal with data and technologies associated with the ICT system.

\subsubsection{Transaction Cost Theory}

The construction industry always happens to incur high transaction costs (TCs), affecting stakeholders involved. It is also one of the main reasons for increasing overall costs of construction projects. TCs generate from the transaction activities occurring during the construction process. TCs have a significant role to determine the "unseen costs" of applying digital technologies to the construction industry. Bean et al. [36] argued that BIM technology can be helpful to solve problems associated with costs of projects. Facility managers always pay attention to the costs coming from the earlier phases of construction projects. Nevertheless, the maintenance and operation costs of a facility account for many times that than its earlier construction costs. Becerik-Gerber et al. [37] indicated that one of the important tasks for facility managers and stakeholders is to reduce the total facility-related costs, such as operation and maintenance costs deriving from design and craftsmanship of building [37].

Becerik-Gerber et al. [37] (p. 5) outlined that "being able to use as-built 3D BIM models to see where the mechanical, plumbing, and electrical components are in a facility enables the localization of this equipment on-site and delivery/display of data relevant to the operational context" and "[ $t]$ his helps lower the cost of maintenance by taking the guesswork out of locating equipment for commissioning, repair, or replacement".

\subsubsection{Organizational Theory}

The study of organizational theory is extensive and difficult to define easily. Sarkis [38] defined organizational theory as management insights that can help explain the behavior, design or structure of an organization. Particularly, there are a number of studies conducted based on the close relationship between the organization and the PM. Among them, Tiwari and Panicker [39] emphasized the importance of PM in FM through a study conducted in India. In particular, they argued that FM can be developed and maintained on the basis of stable financial and strategic planning tools and can be of lasting importance to the organization. Moreover, Meng and Minogue [40] mentioned that a balanced scorecard (BSC) can balance the inside and outside of an organization and emphasized the importance of effective organizational management using effective organizational PM tools.

As Table 5 demonstrates, out of the total number of reviewed articles, 36 articles are non-theory-based studies, which indicates the shortcomings of the theories and methodologies on DT applications in FM and FM PM. Thus, there is a need for more research efforts on theory and methodology developments. As Tables 6 and 7 show, there are insufficient quantitative empirical and literature review articles compared to qualitative empirical studies. Therefore, there is a necessity for more research efforts on quantitative empirical and literature review articles. 
Table 5. Theories employed in articles on Digitalization in FM and FM PM: Contribution of industry 4.0.

\begin{tabular}{|c|c|c|c|c|c|}
\hline Theory & 2010-2012 & 2013-2015 & 2016-2018 & 2019-2021 & Total \\
\hline (Social) network theory & 0 & 0 & 1 & 1 & 2 \\
\hline Agency theory & 2 & 0 & 0 & 0 & 2 \\
\hline Behavioral theory and transaction cost theory & 1 & 0 & 0 & 1 & 2 \\
\hline Gestalt's theory of visual perception & 1 & 0 & 1 & 0 & 2 \\
\hline Knowledge-based view & 0 & 1 & 0 & 3 & 4 \\
\hline Lifecycle thinking approach & 0 & 0 & 1 & 1 & 2 \\
\hline Networking theory & 0 & 1 & 1 & 0 & 2 \\
\hline Organizational and techno-centric theories & 0 & 0 & 1 & 1 & 2 \\
\hline Organizational theory & 0 & 0 & 2 & 2 & 4 \\
\hline $\begin{array}{c}\text { Resource-based and resource orchestration views, } \\
\text { emergent theory }\end{array}$ & 0 & 0 & 0 & 2 & 2 \\
\hline Social theory of organization & 1 & 0 & 1 & 0 & 2 \\
\hline The product lifecycle theory and S-D logic perspective & 1 & 0 & 0 & 1 & 2 \\
\hline The theory of lifecycle assessment & 0 & 1 & 0 & 1 & 2 \\
\hline Transaction cost theory & 0 & 0 & 0 & 3 & 3 \\
\hline Xerox's theory & 1 & 0 & 1 & 0 & 2 \\
\hline No theory (or implicit) & 4 & 4 & 6 & 22 & 36 \\
\hline Total & 11 & 7 & 15 & 38 & 71 \\
\hline
\end{tabular}

Note: Table 5. Knowledge-based view [15,34,35,41], organizational theory [39-42] and transaction cost theory [33,36,37].

Table 6. Theories employed in articles on Digitalization in FM and FM PM: Contribution of industry 4.0.

\begin{tabular}{|c|c|c|c|c|}
\hline Theories & $\begin{array}{l}\text { Quantitative } \\
\text { Empirical }\end{array}$ & $\begin{array}{l}\text { Qualitative } \\
\text { Empirical }\end{array}$ & $\begin{array}{l}\text { Literature } \\
\text { Review }\end{array}$ & Total \\
\hline (Social) network theory & 1 & 1 & 0 & 2 \\
\hline Agency theory & 0 & 2 & 0 & 2 \\
\hline Behavioral and transaction cost theory & 1 & 0 & 1 & 2 \\
\hline Gestalt's theory of visual perception & 1 & 1 & 0 & 2 \\
\hline Knowledge-based view & 2 & 2 & 0 & 4 \\
\hline Lifecycle thinking approach & 0 & 2 & 0 & 2 \\
\hline Networking theory & 1 & 0 & 1 & 2 \\
\hline Organizational and techno-centric theories & 1 & 1 & 0 & 2 \\
\hline Organizational theory & 2 & 1 & 1 & 4 \\
\hline $\begin{array}{c}\text { Resource-based and resource orchestration views, } \\
\text { emergent theory }\end{array}$ & 1 & 1 & 0 & 2 \\
\hline Social theory of organization & 0 & 2 & 0 & 2 \\
\hline The product lifecycle theory and S-D logic perspective & 0 & 2 & 0 & 2 \\
\hline The theory of lifecycle assessment & 1 & 1 & 0 & 2 \\
\hline Transaction cost theory & 2 & 1 & 0 & 3 \\
\hline Xerox's theory & 1 & 1 & 0 & 2 \\
\hline No theory (or implicit) & 8 & 14 & 14 & 36 \\
\hline Total & 22 & 32 & 17 & 71 \\
\hline
\end{tabular}


Table 7. Detailed concepts related to Digitalization in FM and FM PM: Contribution of industry 4.0.

\begin{tabular}{|c|c|c|c|c|}
\hline Concepts Related to Digitalization of FM & $\begin{array}{c}\text { Quantitative } \\
\text { Empirical }\end{array}$ & $\begin{array}{l}\text { Qualitative } \\
\text { Empirical }\end{array}$ & $\begin{array}{l}\text { Literature } \\
\text { Review }\end{array}$ & Total \\
\hline BIM-EDU concept & 0 & 2 & 0 & 2 \\
\hline Building performance attribute data (BPAD) & 0 & 0 & 2 & 2 \\
\hline Business analytics capabilities & 0 & 0 & 1 & 1 \\
\hline Digital boundary & 1 & 0 & 0 & 1 \\
\hline Environmental building performance (EBP) & 2 & 3 & 1 & 6 \\
\hline Green management concept & 1 & 1 & 0 & 2 \\
\hline IoT-BIM concept & 4 & 6 & 3 & 13 \\
\hline Knowledge management concept & 1 & 1 & 1 & 3 \\
\hline Smart agriculture & 1 & 1 & 0 & 2 \\
\hline Smart built environment & 0 & 2 & 2 & 4 \\
\hline Smart campus concept & 1 & 1 & 0 & 2 \\
\hline Smart circular economy & 1 & 1 & 0 & 2 \\
\hline Smart city concept & 2 & 2 & 3 & 7 \\
\hline The concept of benchmarking & 1 & 2 & 1 & 4 \\
\hline The concept of digital sustainability & 2 & 2 & 1 & 5 \\
\hline The concept of digital twin & 1 & 2 & 0 & 3 \\
\hline The concept of enterprise BIM (EBIM) & 0 & 1 & 1 & 2 \\
\hline The concept of intelligent buildings & 1 & 2 & 1 & 4 \\
\hline The concept of sustainability & 2 & 6 & 1 & 9 \\
\hline The concept of the lebesgue & 0 & 1 & 0 & 1 \\
\hline The concept of urban FM & 2 & 1 & 1 & 4 \\
\hline The evolving production concept & 1 & 1 & 0 & 2 \\
\hline Others & 15 & 14 & 8 & 37 \\
\hline Total & 39 & 52 & 27 & 118 \\
\hline
\end{tabular}

\subsection{Research on DT and PM in FM}

Because there is a lack of research articles related to DT in FM and FM PM before industry 4.0, as well as the digital technologies being mostly implemented in construction, architecture and engineering management, we intend to evaluate and analyze all available articles on DT and PM in FM after industry 4.0. Furthermore, even though the literature articles on DT in FM and FM PM have been reviewed by some researchers [7,30,43], there is a need to carry out an up-to-date systematic review on the current status of DT in FM and FM PM. In addition, in our study, we focus on both DT in FM and FM PM in one article, because the past literature review articles covered either DT in FM or FM PM [7,30,43].

In our literature review article, we categorize the literature based on areas of FM such as hard (e.g., building fabric maintenance, landscaping, decoration and refurbishment, M\&E plant maintenance, plumbing and drainage, air-conditioning maintenance, lift and escalator maintenance, fire safety system maintenance, minor project management, etc.) and soft (e.g., cleaning, catering, security, handyman services, waste disposal, recycling, pest control, grounds maintenance, internal plants, etc.) [44] management, as well as focusing on benchmarking and innovation in PM in FM.

Most of the articles that we reviewed are related to hard FM, so our focus is placed on the hard FM services and the role of DT applications and benchmarking and innovation in FM is discussed.

Table 8 illustrates detailed concepts used in the reviewed articles. It explains that BIMIoT, sustainability and smart city concepts are among the most frequently used concepts that can make a huge contribution to increasing FM up to a strategic level. 
Table 8. Detailed concepts related to Digitalization in FM and FM PM: Contribution of industry 4.0.

\begin{tabular}{|c|c|c|c|c|c|}
\hline Concepts Related to Digitalization of FM & 2010-2012 & 2013-2015 & 2016-2018 & 2019-2021 & Total \\
\hline BIM-EDU concept & 1 & 0 & 0 & 1 & 2 \\
\hline Building performance attribute data (BPAD) & 1 & 1 & 0 & 0 & 2 \\
\hline Business analytics capabilities & 0 & 0 & 0 & 1 & 1 \\
\hline Digital boundary & 0 & 0 & 0 & 1 & 1 \\
\hline Environmental building performance (EBP) & 2 & 1 & 1 & 2 & 6 \\
\hline Green management concept & 0 & 1 & 0 & 1 & 2 \\
\hline IoT-BIM concept & 1 & 1 & 3 & 8 & 13 \\
\hline Knowledge management concept & 0 & 1 & 1 & 1 & 3 \\
\hline Smart agriculture & 0 & 1 & 0 & 1 & 2 \\
\hline Smart built environment & 0 & 1 & 1 & 2 & 4 \\
\hline Smart campus concept & 0 & 0 & 0 & 2 & 2 \\
\hline Smart circular economy & 0 & 0 & 1 & 1 & 2 \\
\hline Smart city concept & 1 & 1 & 1 & 4 & 7 \\
\hline The concept of benchmarking & 1 & 2 & 1 & 0 & 4 \\
\hline The concept of digital sustainability & 0 & 2 & 2 & 1 & 5 \\
\hline The concept of digital twin & 0 & 0 & 1 & 2 & 3 \\
\hline The concept of enterprise BIM (EBIM) & 0 & 1 & 0 & 1 & 2 \\
\hline The concept of intelligent buildings & 1 & 0 & 2 & 1 & 4 \\
\hline The concept of sustainability & 1 & 2 & 2 & 4 & 9 \\
\hline The concept of the Lebesgue & 0 & 0 & 0 & 1 & 1 \\
\hline The concept of urban FM & 0 & 2 & 1 & 1 & 4 \\
\hline The evolving production concept & 1 & 0 & 0 & 1 & 2 \\
\hline Others & 3 & 5 & 15 & 14 & 37 \\
\hline Total & 13 & 22 & 32 & 51 & 118 \\
\hline
\end{tabular}

\subsubsection{Hard FM (BIM, IoT, GIS)}

Dahanayake and Sumanarathna [14] argued that the integration of BIM and IoT technologies transforms traditional FM into a digitalized one. These technologies increase the efficiency of building management. "The BIM-IoT technologies can be effectively integrated into six asset management functions such as energy management, operations and maintenance management, space management, FM project management, emergency management and quality management" [14] (p. 3). Mannino et al. [45] (p. 14) asserted that "the integration of end users in the process of maintenance can reduce the existing barcode system limits by using BIM-IoT system". This is also able to overcome the limitations of building management systems for the failure of localization. In addition, the research framework suggests a number of advantages. For instance, it can give an opportunity to identify every element of building. In addition, whole management activities are controlled through a special integrated system [45]. Mirarchi et al. [8] propose a theoretical framework for the integration of digital technologies in FM. It is found that "the framework allows end user to integrate with the maintenance processes by the help of smart technologies" and " $\mathrm{t}]$ his integration process can overcome limits of barcode systems and building management systems on localization failure" [8] (p. 5).

Alhamami et al. [46], in their case study, showed that BIM makes a huge contribution to the construction industry of countries in Europe because BIM training and educational projects can be implemented to offer European nations idiosyncratic energy strategies [46].

\subsubsection{Benchmarking in FM}

Adewunmi and Ajayi [41] (p. 2.) affirmed that "benchmarking is a continuous, systematic process for evaluating the products, services or work processes of organizations that are recognized as representing best practices for the purpose of organizational improvement." According to Adewunmi and Ajayi [41], benchmarking is regarded as a superb measurement method in the precise and efficient comparison and evaluation of one facility to other ones. In addition, companies employ benchmarking measurement means for 
setting up performance standards and to augment potentials through joint best practices. Although there can be some rating systems of the quality, the most often utilized standards for the measurement of facility performance are cost centered [41].

Adewunmi and Ajayi [41] (p. 3), in their article, also found that "in case of informal benchmarking, benchmarking tools help to increase performance level and service quality of facility", and "[i]n case of formal benchmarking, benchmarking help making strategies which lead firms to be competitive in the industry" [41]. It is found that the methodology presented in the research work written by Róka-Madarász [47] is applicable for benchmarking of facility maintenance management. The findings in her research work clearly support "the need to conduct a similar survey among other types of organizations to determine whether the criteria for good practice are similar to those of higher education institutions and whether the model can be applied to other types of organizations" [47] (p. 2).

According to Adewunmi and Ajayi [41], utilizing benchmarking tools enables facility managers to have insights into what is crucial in a benchmarking project and gives chances to understand the lessons from benchmarking experiences utilized in different companies [41].

\subsubsection{Innovation in FM}

Nardelli et al. [48] (p. 16) pointed out that most articles focusing on the generic innovation in management literature have recently realized that "the defective logic that innovation is tightly connected to or generated from information communication technologies is exposed" and "[i]nnovation allows facility managers to discovery mistakes and learn from them and discover a result, which become eventually beneficial".

Most researchers have paid their attention to the external and internal aspects related to generic innovation but, recently, more research focus on innovation has been placed in maintenance management. Pitt et al. [49] found that using strategic maintenance management systems in FM can prop up the innovation process within the organization. Because an innovation process becomes a mandate to the business to strengthen competitive environment, the decision-making facility maintenance strategy can be very important [49].

Mudrak et al. [50], in their study, explored FM organizations that innovate mildly, which means that the innovation process in FM is gradually increasing because of the regular changing of decision making in asset management projects, as well as client organizations that have been changing their demand, so it makes FM innovations more increment [50].

Pitt et al. [49] (p. 11) also indicated that "in maintenance management, service providers need to maintain a process of continual innovation and improvement in order to meet the demands of the client or client group and customers", and thus "competition within the maintenance management field may be defined as originating within the aspirations of the client group. It is passed on as a demand through the aspirations of the client." The innovation management plays a significant role not only in the provision of innovative solutions in facility maintenance management but also in the establishment of a creative environment where solutions are made, developed and implemented.

Innovative processes in FM are mainly based on the digital applications such as BIM, GIS, point cloud, photogrammetry and 3D laser scanning. Application of these digital technologies in FM improves the safety of the built environments and maintenance and land management process. Erdelj et al. [28] propose a method allowing UAS to provide a continuous uninterrupted structural inspection service (p.10). Furthermore, Yan et al. [51] proposed a method that uses digital technologies such as GIS and remote sensing, photogrammetry and Moderate Resolution Imaging Spectroradiometer (MODIS) for structural inspection of Three Gorges Dam in Dongting Lake, China, and for extracting a record of the lake's bottom topography from 2003 to 2011. The result indicated that the lake's bottom topography has showed uneven erosion and downfall regarding time and space over the last nine years [51] (p. 4). 


\subsubsection{Sustainability in Facilities Management (FM)}

During the last decades, many research methodologies for the evaluation of sustainable FM issues are discussed in numerous research articles related to FM. Moreover, researchers on sustainability have concentrated on the role of DT in sustainable FM. According to Peron et al. [52], some new technologies such as 3D mapping, indoor positioning system (IPS), Motion Capture Mirco System (MoCap) and Immersive Reality (IR) are used in sustainable FM. Using these technologies helps to reconfigure the structure that has a positive impact on the three pillars of sustainability concepts. As a result, the incurring costs are reduced and environmental and social challenges are mitigated [52].

Cricelli and Strazzullo [53] underlined and classified the key sustainability standards related to digital technologies. Especially, "the digital technologies improve the interrelation of goods and plants, the value chain and managers to attain a sustainable production cycle" and "provide firms with the opportunities to encourage innovation process and entrepreneurship, rise of the market share, decrease energy waste, and recycle the material" [53] (p. 10). Furthermore, according to Maslesa and Jensen [34], various IT systems are frequently utilized for managing environmental building performance (EBP). EBP is mainly reflected in energy management with a robust emphasis on controlling and reporting heating, water and electricity consumption. Moreover, "in some IT systems greenhouse gas emissions generated from energy consumption can be calculated, whilst other building materials and recycling potentials are not appropriately maintained by the IT systems mentioned in this study" [34] (p. 10).

In some research articles, the impact of DT applications on sustainable FM was discussed. For instance, Petri et al. [54] explored how to use BIM for energy efficiency in buildings in the operation phase with the aim of achieving carbon emissions. Furthermore, two contributions were implied, a BIM-oriented method on energy optimization of buildings and a case study of the European research project Sporte2, to indicate the advantages of BIM in energy efficiency [54]. Barletta et al. [55] proposed a new method framework for evaluating and comparing social, economic and environmental effects occurring from facility changes for electronic waste treatment. This method gives crucial information for decision making and assists in evaluating the fundamental factors that have effects on e-waste management systems [55]. Furthermore, Zhang et al. [56] explored BIM-based methodologies for pre-construction design, verification and post-construction FM of smart buildings in the smart grid era. A prototype of a smart house energy management system utilizing Revit and the xBIM toolkit was also implemented and successfully demonstrated in their research article.

Many research works make a big contribution to the understanding of digital tools in the development of smart city governance. Alam [22] argued that people living in smart city environments may obtain a great opportunity to utilize their mobile phones through connected vehicles and smart homes. In case the tools are connected to the physical urban systems, it can decrease costs and enhance efficiency in smart city. Alam [22] also argued the role of cloud-based IoT applications in smart city development. It is found that, through the help of the IoT system, the resource transmission of cities can be improved as well as environmental pollutants removed and waste management and transport controlling systems developed [22].

Alhamami et al. [46] investigated promoting energy efficiency in the built environment through the adaptation of BIM and IoT training and education, providing cases such as a shopping and commercial development center located in Pori, southwestern Finland, and the European sport and recreation building stock in Italy. By analyzing the cases, authors aim to define how BIM and IoT can promote and maintain energy-efficient designs, construction and maintenance of a facility in different ways. The result indicated that the digital technologies in the European construction industry through the application of $\mathrm{BIM}$ and IoT, or the integration of them, can improve and develop energy strategies for European nations in terms of sustainable FM. 


\section{Directions for Future Research}

Our systematic review article presents an overview of DT applications in FM and FM $\mathrm{PM}$, including future research directions for additional research analysis.

\section{$D T s$ in FM and FM PM}

Past research studies were restricted on the monitoring of facilities, so an additional research study is needed. Villa et al. [57] suggested there is a need for further research on the increase in connectivity of building facilities and evaluation of the system's integration with asset managers and users to evaluate its safety, repeatability, controllability and simplicity for implementation. Moreover, future research study should focus on utilizing collected data from the decision support system to maintain predictive maintenance management of buildings. Since the system is utilized for artificial intelligence (AI), machine learning (ML) and predictive maintenance management systems [57]. According to Mannino et al. [45], additional research works are needed for automatically recognizing critical locations where types of sensors are necessary to observe crucial elements.

Furthermore, future studies are required to focus on interoperability of BIM methodology. According to Mannino et al. [45], future research works should concentrate more on the interoperability and open BIM methodologies in the FM field. In this regard, the issues should be focused on the scarce as-built information. In addition, data integration support, interoperability and open BIM makes it possible to attain superior solutions for FM [45]. Moreover, the interoperability of data/information on the implementation of DT application from differential sources is required to further research work as well. Mannino et al. [45] also argued that the interoperability issues will be the main problem for researchers because of multiple and differential data/information sources and platforms.

BIM concept has recently been used for transportation infrastructures such as airports, highways, bridges, bus terminals and so on, but it is still in the early stage. In the future, more well-founded research work will be needed to test and apply the BIM concept for smart transportation infrastructure. Yang et al. [58] affirmed that the better possible application might be visualization promoted by BIM for transportation infrastructure, because it is proven that visualization of a facility is the most effective in the implementation of both equipment scheduling and the evaluation of facility performance [58].

BIM based methods have been recently combined with GIS-based approaches in the analysis and modeling of energy systems. Recently, 3D modeling has been implemented to calculate solar power using façade visibility [59]. Three-dimensional analysis algorithms together with three-dimensional modeling plays a significant role in future modeling of energy system. Future research is needed to use the integration of 3D analysis algorithms, such as ray tracing algorithm, high solution building data analysis, building part parameters (e.g., walls, windows, line networks, etc.) and the perfect cross integration of BIM and GIS [59].

There is a need for the unified data model to support the integration of different database sources, such as renewable energy powers, typologies of line network, statistical and meteorological data, 3D building models, power plants energy storage facilities, etc. According to researchers Resch et al. [60], the energy sector has not yet been entered into geospatial data storage and modeling concepts contrasted to many other application sectors [60]. Therefore, it should raise awareness of the GIS-based methodology and spatial data infrastructure concept for sustainable FM in future studies.

More systematic research efforts are required on performance management in FM because there is a lack of data and theories that drive performance management. According to researchers Simões et al. [61] and Ginthotavidana and Waidyasekara [42], future research efforts can develop a PM system with many significant key performance indicators (KPIs), with new methodologies and theoretical constructs to reduce KPIs subjectivity and use more practical applications. This is because new methodology and theory could be an important source for the advancement of knowledge in any scientific field [42,61]. 


\section{Conclusions}

This article provides an overview of the important aspects of the existing body of literature related to DT application in the field of FM and FM PM and the contribution of industry 4.0. The results of our analysis of previous studies show that, despite continuous research, there is a lack of research review articles related to the integration of DT and FM PM.

The first contribution of our study is to present a holistic literature review by integrating both research streams of studies on DT in FM and FM PM. Integrating research studies related to DT in FM and FM PM in a single literature review article makes our study distinctive from other literature review studies. Through the analysis of previous review articles, we found that there is a need for more systematic research efforts on theory and methodology developments of research articles on the topic. Thus, our theoretical approach is the second contribution to the furthering theory and methodology development regarding DTs in FM and FM PM. Our literature review analysis showed that there has been no literature review studies on DT in FM and FM PM that have reviewed country distributions of FM samples. Thus, it is the third contribution of our review article which can help to obtain a broad understanding of the topic. Furthermore, it can be an important direction for future researchers of FM study, because the country distribution of review study provides researchers with important information about which region has a need for more research studies or which countries have not yet been studied on DT in FM and FM PM.

It is hoped that the abovementioned contributions have greater merits to providing a cornerstone for further advancement and will encourage researchers and facility managers to drive the DTs in FM and FM PM agenda. Despite the abovementioned contributions, our review article has one limitation, that only limited numbers of DT applications such as BIM, GIS, IoT and reality capture technology (e.g., laser scanning and photogrammetry) are covered. Future research studies can extend the types of DT applications in the field of FM.

Our study offers four propositions for future research directions. Past research studies were restricted on the monitoring of facilities so that additional research studies are needed to: (1) focus on interoperability issues between different software applications of DTs in FM, (2) test and apply the BIM concept for smart transportation infrastructure, (3) use the integration of 3D analysis algorithms and the perfect cross integration of BIM and GIS and (4) undertake more systematic research efforts on theory and methodology developments. So, these four agendas are required on performance management in FM. Taken together, we hope that this study will contribute to the development of research linking DT in FM and FM PM.

Author Contributions: Conceptualization, I.O.I. and Y.-S.R.; methodology, I.O.I. and Y.-S.R.; software, Y.-S.R.; validation, Y.-S.R. and J.Y.L.; formal analysis, I.O.I.; investigation, I.O.I. and Y.-S.R.; resources, J.Y.L.; data curation, I.O.I.; writing—original draft preparation, I.O.I. and Y.-S.R.; writing—review and editing, I.O.I., Y.-S.R. and J.Y.L.; visualization, Y.-S.R.; supervision, J.Y.L.; project administration, J.Y.L.; funding acquisition, J.Y.L. All authors have read and agreed to the published version of the manuscript.

Funding: This research received no external funding.

Conflicts of Interest: The authors declare no conflict of interest.

\section{References}

1. ISO (International Organization for Standardization). Facility Management—Vocabulary (ISO 41011: 2017). Available online: https: / / bit.ly/2MEuxRY (accessed on 18 October 2021).

2. IFMA (International Facility Management Association). What Is Facility Management. Available online: https://www.ifma.org/ about/what-is-facility-management (accessed on 18 October 2021).

3. Pilanawithana, N.M.; Sandanayake, Y.G. Positioning the facilities manager's role throughout the building lifecycle. J. Facil. Manag. 2017, 15, 376-392. [CrossRef] 
4. Xu, J.; Lu, W.; Xue, F.; Chen, K. 'Cognitive facility management': Definition, system architecture, and example scenario. Autom. Constr. 2019, 107, 102-922. [CrossRef]

5. Alexander, K. Facilities management practice. Facilities 1992, 10, 11-18. [CrossRef]

6. Kindcaid, D. Integrated facility management. Facilities 1994, 12, 20-23. [CrossRef]

7. Wong, J.K.W.; Ge, J.; He, S.X. Digitisation in facilities management: A literature review and future research directions. Autom. Constr. 2018, 92, 312-326. [CrossRef]

8. Mirarchi, C.; Pavan, A.; Marco, F.D.; Wang, X.; Song, Y. Supporting Facility Management Processes through End-Users' Integration and Coordinated BIM-GIS Technologies. Int. J. Geoinf. 2018, 7, 191. [CrossRef]

9. Koch, C.; Hansen, G.K.; Jacobsen, K. Missed opportunities: Two case studies of digitalization of FM in hospitals. Facilities 2019, 37, 381-394. [CrossRef]

10. Neely, A. The performance measurement revolution: Why now and what next? Int. J. Oper. Prod. Manag. 1999, 19, 205-228. [CrossRef]

11. Koleoso, H.A.; Omirin, M.M.; Adewunmi, Y.A. Performance measurement scale for facilities management service in LagosNigeria. J. Facil. Manag. 2017, 15, 128-152. [CrossRef]

12. Kristoffersen, E.; Mikalef, P.; Blomsma, F.; Li, J. The effects of business analytics capability on circular economy implementation, resource orchestration capability, and firm performance. Int. J. Prod. Econ. 2021, 239, 108205. [CrossRef]

13. Bröchner, J.; Haugen, T.; Lindkvist, C. Shaping tomorrow's facilities management. Facilities 2019, 37, 366-380. [CrossRef]

14. Dahanayake, K.C.; Sumanarathna, N. IoT-BIM-based digital transformation in facilities management: A conceptual model. J. Facil. Manag. 2021, 1472-5967. [CrossRef]

15. Liu, R.; Issa, R.R.A. Survey: Common Knowledge in BIM for Facility Maintenance. J. Perform. Constr. Facil. 2016, $30,04015033$. [CrossRef]

16. Chong, H.Y.; Wong, J.S.; Wang, X. An explanatory case study on cloud computing applications in the built environment. Autom. Constr. 2014, 44, 152-162. [CrossRef]

17. Stojanovic, V.; Trapp, M.; Richter, R.; Hagedorn, B.; Döllner, J. Towards the generation of digital twins for facility management based on 3D point clouds. J. Health Organ. Manag. 2018, 270-279.

18. Wang, H.; Pan, Y.; Luo, X. Integration of BIM and GIS in sustainable built environment: A review and bibliometric analysis. Autom. Constr. 2019, 103, 41-52. [CrossRef]

19. Zhang, W.; Wong, N.H.; Zhang, Y.; Chen, Y.; Tong, S.; Zheng, Z.; Chen, J. Evaluation of the photovoltaic potential in built environment using spatial data captured by unmanned aerial vehicles. Energy Sci. Eng. 2019, 7, 2011-2025. [CrossRef]

20. Sun, Z.; Zhang, Y. Using drones and 3D modeling to survey Tibetan architectural heritage: A case study with the multi-door stupa. Sustainability 2018, 10, 2259. [CrossRef]

21. Patel, K.K.; Patel, S.M. Internet of Things-IOT: Definition, Characteristics, Architecture, Enabling Technologies, Application \& Future Challenges. Int. J. Eng. Sci. Comput. 2016, 210-215.

22. Alam, T. Cloud-Based IoT Applications and Their Roles in Smart Cities. Smart Cities 2021, 4, 1196-1219. [CrossRef]

23. Evjen, T.Å.; Hosseini Raviz, S.R.; Petersen, S.A.; Krogstie, J. Smart facility management: Future healthcare organization through indoor positioning systems in the light of enterprise BIM. Smart Cities 2020, 3, 793-805. [CrossRef]

24. Xu, J.; Chen, K.; Zetkulic, A.E.; Xue, F.; Lu, W.; Niu, Y. Pervasive sensing technologies for facility management: A critical review. Facilities 2020, 38, 161-180. [CrossRef]

25. Hou, L.; Wang, Y.; Wang, X.; Maynard, N.; Cameron, I.T.; Zhang, S.; Jiao, I. Combining Photogrammetry and Augmented Reality Towards an Integrated Facility Management System for the Oil Industry. Proc. IEEE 2014, 102, 204-220. [CrossRef]

26. Cipriani, A.; Citton, P.; Romano, M.; Fabbi, S. Testing two open-source photogrammetry software as a tool to digitally preserve and objectively communicate significant geological data: The Agolla case study (Umbria-Marche Apennines). Ital. J. Geosci. 2016, 135, 199-209. [CrossRef]

27. Wang, Q.; Tan, Y.; Mei, Z. Computational Methods of Acquisition and Processing of 3D Point Cloud Data for Construction Applications. Arch. Comput. Methods Eng. 2020, 27, 479-499. [CrossRef]

28. Erdelj, M.; Saif, O.; Natalizio, E.; Fantoni, E. UAVs that fly forever: Uninterrupted structural inspection through automatic UAV replacement. Ad Hoc Netw. 2019, 94, 101612. [CrossRef]

29. Gallo, I.G.; Martínez-Corbella, M.; Sarro, R.; Iovine, G.; López-Vinielles, J.; Hérnandez, M.; García-Davalillo, J.C. An Integration of UAV-Based Photogrammetry and 3D Modelling for Rockfall Hazard Assessment: The Cárcavos Case in 2018 (Spain). Remote Sens. 2021, 13, 3450. [CrossRef]

30. Amos, D.; Musa, Z.N.; Au-Yong, C.P. A review of facilities management performance measurement. Prop. Manag. 2019, 37, 490-511. [CrossRef]

31. Amaratunga, D.; Baldry, D. A conceptual framework to measure facilities management performance. Prop. Manag. 2003, 21, 171-189. [CrossRef]

32. Koleoso, H.; Omirin, M.; Adewunmi, Y.; Babawale, G. Applicability of existing performance evaluation tools and concepts to the Nigerian facilities management practice. Int. J. Strateg. Prop. Manag. 2013, 17, 361-376. [CrossRef]

33. Liyanage, C.; Egbu, C. Controlling healthcare associated infections (HAI) and the role of facilities management in achieving "quality" in healthcare: A three-dimensional view. Facilities 2005, 23, 194-215. [CrossRef] 
34. Maslesa, E.; Jensen, P.A. Managing environmental building performance through IT systems. Facilities 2019, 38, $235-251$. [CrossRef]

35. Pathirage, C.; Haigh, R.; Amaratunga, D.; Baldry, D. Knowledge management practices in facilities organizations: A case study. J. Facil. Manag. 2008, 6, 5-22. [CrossRef]

36. Bean, T.K.; Mustapa, F.D.; Mustapa, M. Unbundling Transaction Cost Components in Building Information Modeling Adoption Procurement. Int. J. Recent Technol. Eng. 2019, 8, 333-338. [CrossRef]

37. Becerik-Gerber, B.; Jazizadeh, F.; Li, N.; Calis, G. Application areas and data requirements for BIM enabled facility management. J. Constr. Eng. Manag. 2012, 138, 431-442. [CrossRef]

38. Sarkis, J.; Zhu, Q.; Lai, K.-H. An organizational theoretic review of green supply chain management literature. Int. J. Prod. Econ. 2011, 130, 1-15. [CrossRef]

39. Tiwari, P.; Panicker, S. Sustainability Balanced Scorecard as a Framework for Performance Measurement in Facility ManagementA Literature Review. Pac. Bus. Rev. Int. 2017, 10, 121-127.

40. Meng, X.; Minogue, M. Performance measurement models in facility management: A comparative study. Facilities 2011, 29, 472-484. [CrossRef]

41. Adewunmi, Y.A.; Ajayi, O.D. Attitudes of Nigerian facilities management professionals to the benefits of benchmarking. Facilities 2016, 34, 468-492. [CrossRef]

42. Ginthotavidana, S.S.C.; Waidyasekara, K.G.A.S. A performance measurement model for the housekeeping services in healthcare facilities. Facilities 2021, 25. [CrossRef]

43. Matarneh, S.T.; Danso-Amoako, M.; Al-Bizri, S.; Gaterell, M.; Matarneh, M. Building information modeling for facilities management: A literature review and future research directions. J. Build. Eng. 2019, 24, 100755. [CrossRef]

44. Robinson, H.S.; Scott, J. Service delivery and performance monitoring in PFI/PPP projects. Constr. Manag. Econ. 2009, 27, 181-197. [CrossRef]

45. Mannino, A.; Dejaco, M.C.; Cecconi, F.R. Building Information Modelling and Internet of Things Integration for Facility Management-Literature Review and Future Needs. Appl. Sci. 2021, 11, 3062. [CrossRef]

46. Alhamami, A.; Petri, I.; Rezgui, Y.; Kubicki, S. Promoting Energy Efficiency in the Built Environment through Adapted BIM Training and Education. Energies 2020, 13, 2308. [CrossRef]

47. Róka-Madarász, L. Performance measurement for maintenance management of real estate. Acta Polytech. Hung. 2011, 8, 161-172.

48. Nardelli, G.; Jensen, J.O.; Nielsen, S.B. Facilities management innovation in public-private collaborations: Danish ESCO projects. J. Facil. Manag. 2015, 13, 185-203. [CrossRef]

49. Pitt, M.; Goyal, S.; Sapri, M. Innovation in facilities maintenance management. Build. Serv. Eng. Res. Technol. 2006, 27, 153-164. [CrossRef]

50. Mudrak, T.; Wagenberg, A.V.; Wubben, E. Innovation process and innovativeness of facility management organizations. Facilities 2005, 23, 103-118. [CrossRef]

51. Yan, Y.; Xiao, F.; Du, Y. Construction of lake bathymetry from MODIS satellite data and GIS from 2003 to 2011. Chin. J. Oceanol. Limnol. 2014, 32, 720-731. [CrossRef]

52. Peron, M.; Fragapane, G.; Sgarbossa, F.; Kay, M. Digital Facility Layout Planning. Sustainability 2020, 12, 3349. [CrossRef]

53. Cricelli, L.; Strazzullo, S. The Economic Aspect of Digital Sustainability: A Systematic Review. Sustainability 2021, $13,8241$. [CrossRef]

54. Petri, I.; Kubicki, S.; Rezgui, Y.; Guerriero, A.; Li, H. Optimizing Energy Efficiency in Operating Built Environment Assets through Building Information Modeling: A Case Study. Energies 2017, 10, 1167. [CrossRef]

55. Barletta, I.; Larborn, J.; Mani, M.; Johannson, B. Towards an Assessment Methodology to Support Decision Making for Sustainable Electronic Waste Management Systems: Automatic Sorting Technology. Sustainability 2016, 8, 84. [CrossRef]

56. Zhang, J.; Seet, B.-C.; Lie, T.T. Building Information Modelling for Smart Built Environments. Buildings 2015, 5, 100-115. [CrossRef]

57. Villa, V.; Naticchia, B.; Bruno, G.; Aliev, K.; Piantanida, P.; Antonelli, D. IoT Open-Source Architecture for the Maintenance of Building Facilities. Appl. Sci. 2021, 11, 5374. [CrossRef]

58. Yang, Y.; Han, M.; Zeng, Q.; Sun, Y. Adopting Building Information Modeling (BIM) for the Development of Smart Buildings: A Review of Enabling Applications and Challenges. Adv. Civ. Eng. 2021, 2021, 8811476. [CrossRef]

59. Albrecht, F.; Moser, J.; Hijazi, I. Assessing façade visibility in 3D city models for city marketing. Int. Arch. Photogramm. Remote Sens. Spat. Inf. Sci. 2013, XL-2/W2, 1-5. [CrossRef]

60. Resch, B.; Sagl, G.; Törnros, T.; Bachmaier, A.; Eggers, J.-B.; Herkel, S.; Narmsara, S.; Gündra, H. GIS-Based Planning and Modeling for Renewable Energy: Challenges and Future Research Avenues. ISPRS Int. J. Geo-Inf. 2014, 3, 662-692. [CrossRef]

61. Simões, J.M.; Gomes, C.F.; Yasin, M.M. A literature review of maintenance performance measurement: A conceptual framework and directions for future research. J. Qual. Maint. Eng. 2011, 17, 116-137. [CrossRef] 